\title{
High Temperature Effects in Fused Silica Optical Fibers
}

\author{
Krzysztof Borzycki, Marek Jaworski, and Tomasz Kossek \\ National Institute of Telecommunications, Warsaw, Poland
}

https://doi.org/10.26636/jtit.2021.153521

\begin{abstract}
Fire-resistant fiber optic cables used in safety and monitoring systems playing an essential role in fire fighting and building evacuation procedures are required to temporarily maintain optical continuity when exposed to fire. However, the use of fused silica fiber at temperatures between $800^{\circ} \mathrm{C}$ and $1000^{\circ} \mathrm{C}$ is associated with two highly undesirable phenomena. Thermal radiation (incandescence) of optical fibers, with its intensity and spectral distribution being proportional to additional attenuation observed in the fiber's hydroxyl absorption bands ("water peaks") is one of them. The other consists in penetration of thermal radiation from the surroundings into the fiber, due to defects in glass, causing light scattering and resulting in fiber brittleness. Thermal radiation is a source of interference in fiber attenuation measurements performed during fire tests and affects normal operation of fiber optic data links in the event of a fire. In this article, results of laboratory tests performed on a telecom single mode and multimode fibers subjected to temperatures of up to $1000^{\circ} \mathrm{C}$ are presented.
\end{abstract}

Keywords-fire-resistant fiber optic cable, fire test, fused silica optical fiber, incandescence spectrum, thermal deterioration, thermal radiation.

\section{Introduction}

Optical fibers used in fire-resistant cables should be capable of remaining operational, over a specific period of time, during a fire incident. While fused silica fibers are capable of withstanding temperatures of up to $1000^{\circ} \mathrm{C}$ while retaining their optical continuity, their properties degrade. In particular, time-dependent incandescence (thermal radiation) of the fiber itself occurs, and thermal radiation from the hot surroundings is coupled into the fiber. Both these phenomena are a cause of optical interference affecting transmission of data over hot fibers, and their testing. The performance of an optical fiber in a cable affected by fire depends on the following:

- properties of the fiber itself, i.e. attenuation, incandescence, light scattering, and coupling by defects,

- protection against fire and mechanical damage offered by heat-resistant components of the cable.

This paper focuses primarily on the first of the abovementioned items and describes the variations in optical properties of standard, telecom type fused silica optical fibers at high temperatures in the event of a fire (or during a fire test). In addition to peak temperature, duration of exposure is important as well, as the performance of a heated fiber degrades slowly due to the following:

- migration of dopants $\left(\mathrm{F}_{2}, \mathrm{GeO}_{2}\right)$, which distorts the fiber's refractive profile,

- appearance of defects that are caused by the fact that fused silica turns into cristobalite and causes the glass to crack.

According to the analysis presented in [1], the migration of the most common $\mathrm{GeO}_{2}$ dopant was of no importance as a fused silica fiber was heated to $1000^{\circ} \mathrm{C}$ for up to $100 \mathrm{~h}$. The formation of microscopic defects in fused silica fibers has been reported in [2] and was also observed during the experiments performed. Defects, i.e. cracks in cladding, are capable of introducing infrared radiation from the hot surroundings into the fiber's core. This radiation is routed towards the fiber's end, thus creating interference affecting the operation of the receiver in a data link or of the optical power meter during a fire test. A hot optical fiber no longer is a "dark" interference-free transmission medium.

The investigations presented in this paper were triggered by technical problems encountered in measuring the attenuation of optical fibers during a fire test. Intense thermal emissions originating from a multimode fiber at or above $900^{\circ} \mathrm{C}$ prevented loss measurements from being performed with a low power signal source and an optical power meter. This issue was previously unknown in the literature, as fire-resistant cables had predominantly the form of power and control cables with copper conductors. Contemporary standards providing for the monitoring of attenuation of optical fibers [3], [4] do not provide for any methods for the elimination of interference resulting from thermal emissions taking place in the tested fiber as well.

Section 2 of this paper offers a short review of fire-retardant and fire-resistant fiber cables, while fire testing procedures applicable to the latter are presented briefly in Section 3 . Section 4 outlines our test campaign, while Sections 5, 6 and 7 present selected test results for single-mode and multimode fibers, including light scattering and fiber deterioration due to thermally-induced defects. Section 8 reviews physical mechanisms and selected characteristics of thermal radiation encountered in hot fibers. Discussion of the 
results and plans concerning further work are presented in Section 9, while Section 10 concludes the paper.

\section{Indoor Cables on Fire}

Fiber optic cables installed in commercial buildings are required to comply with fire safety regulations and shall pass the fire tests required. Two broad groups of such cables capable of meeting different requirements may be distinguished:

- fire- (or flame-) retardant cables,

- fire-resistant cables.

While these terms sound similar, their meanings are quite different.

\subsection{Fire-retardant Cables}

As far as cables for data communication networks which are not required to remain operational in the event of a fire are concerned, fire safety requirements applicable in the EU (US standards are substantially different) specify the following:

a) fire propagation along the cable for given installation conditions: vertical shaft or horizontal space under a false ceiling, single cable or cable harness, type of fire source, its thermal power and duration of exposure,

b) optical density of smoke (opaque smoke hinders evacuation from the danger zone),

c) concentration of corrosive and toxic compounds: chlorine, fluorine and bromine compounds, hydrocyanic acid $(\mathrm{HCN})$, sulfur dioxide $\left(\mathrm{SO}_{2}\right)$, etc. in the smoke.

Cables meeting the abovementioned requirements are classified as halogen-free fire retardant (HFFR) cables. In order to meet the requirements set out in (b) and (c), the use of materials containing halogens $(\mathrm{Cl}, \mathrm{F}, \mathrm{Br})$ needs to be avoided, especially in jacket or sheath of the cable. Examples of non-compliant fire-retardant materials widely used in cable manufacturing include polyvinyl chloride (PVC), polyvinylidene fluoride (PVDF) and all polymeric materials with bromine compounds added.

These materials have been replaced with halogen-free thermoplastic polymers, typically polyethylene and its copolymers, or ethylene-vinyl acetate (EVA) which are highly flammable in their pure form, but become flame-retardant after addition of $60-70 \%$ (weight-wise) of a fine powder (1-3 $\mathrm{\mu m}$ ) inorganic filler serving the purpose of a halogenfree flame-retardant and smoke suppressant. Once heated to its decomposition temperature, the filler releases large amounts of water vapors temporarily blocking access of air to the polymer and carrying the heat away. Instead of burning, slow charring takes place. However, once all water evaporates, the hot polymer begins to burn rapidly.
$\mathrm{MDH}$ or magnesium dihydrate $-\mathrm{Mg}(\mathrm{OH})_{2}$, decomposing to water and solid magnesia $(\mathrm{MgO})$ after being heated to over $300^{\circ} \mathrm{C}$, is the most common filler of this type. ATH or alumina trihydrate $\left(\mathrm{Al}_{2} \mathrm{O}_{3} \cdot 3 \mathrm{H}_{2} \mathrm{O}\right)$ is a less expensive filler, but its relatively low decomposition temperature of $200-220^{\circ} \mathrm{C}$ makes it incompatible with several polymers requiring higher extrusion temperatures, including medium and high density polyethylene (MDPE, HDPE), polypropylene (PP), polyamides (PA) or poly(butylene terephthalate) (PBT) widely used for manufacturing fiber optic cables. ATH and MDH fillers are completely non-toxic. Other similar materials exist as well, but are rarely used.

Halogen-free fire/flame-retardant jacketing compounds are known as low smoke zero halogen (LSZH) materials.

A review of fire testing procedures applicable to communication and data transmission cables, along with references to applicable standards, is presented in IEC TR 62222 [5]. Detailed requirements, as well as descriptions of the test methods and hardware, are presented in several IEC/EN standards, applying to thin (maximum diameter of $20 \mathrm{~mm}$ ) and metal-free indoor fiber optic cables [6]-[15]. The remaining standards apply to HFFR power, control and data transmission cables with metallic conductors.

HFFR cables are used to protect humans' life, as well as to ensure the safety of equipment and buildings by limiting or delaying the spread of fire and the amount of smoke and toxic or corrosive substances produced. However, ordinary fire-retardant cables are not required to remain electrically or optically functional, to retain continuity, to ensure stable transmission properties of optical or electrical circuits, to prevent short circuits, etc., when exposed to fire. A system utilizing these cables fails under such circumstances, either due to a disruption in communications or to the loss of power supply to remote hardware, such as video cameras. Cables from this group are out of the scope of this paper.

\subsection{Fire-resistant Cables}

Substantially different requirements apply to cables - either of the copper or fiber optic variety used in fire detection and protection systems, e.g. in smoke detectors, alarm devices, or surveillance cameras, and for ensuring emergency communications in the event of a fire. These cables must remain functional for a period of time that is necessary to alert security staff, police and fire services, to evacuate the affected area and to organize fire-fighting efforts. Cables of this type are known as fire-resistant (FR).

In addition to the requirements set forth in Subsection 2.1, fire-resistant cables shall:

d) retain continuity and stability of critical parameters of electrical or optical circuits in the event of a fire, for 15 to 120 minutes, depending on cable fire classification,

d) survive mild mechanical shocks and periodic sprinkling with water (optionally).

The applicable tests are defined in standards [16]-[21]. While fire test methods and severity, defined primarily by 
peak temperature and test duration, vary considerably, the attenuation range permitted for optical fibers within the cable and its test methods are identical, depending on the type of fiber only [22].

Standardized fire test temperatures range from $800^{\circ} \mathrm{C}$ to over $1000^{\circ} \mathrm{C}$. Hence, only optical fibers made of fused silica $\left(\mathrm{SiO}_{2}\right)$ are suitable for such applications. In order to retain compatibility with industry-wide splicing techniques and tooling, standard single-mode or multi-mode fibers with $125 \mu \mathrm{m}$ cladding diameter in polymer protective coatings are used. While fused silica is capable of temporarily withstanding exposure to $1000^{\circ} \mathrm{C}$ without melting or significant degradation of its properties, polymer coatings fail: they decompose, leaving carbon residues, and then begin to burn at $500-600^{\circ} \mathrm{C}$ when exposed to oxygen. Special high-temperature fibers, such as fused silica fibers with nickel coating or fibers made of crystalline alumina $\left(\mathrm{Al}_{2} \mathrm{O}_{3}\right)$, are capable of surviving heating to $1000^{\circ} \mathrm{C}$ without damage and are used in high-temperature fiber sensors, but not suitable for communication cables due to their high attenuation and lack of cladding, unsuitability for fusion splicing and brittleness (alumina fibers).

Telecom fibers have primary protective coatings made of UV - curable dual acrylate. Their maximum operating temperature is $85^{\circ} \mathrm{C}$ (continuous) and $200^{\circ} \mathrm{C}$ over a period of several days [23], [24]. Fibers with high-temperature acrylate coatings for continuous use in temperatures of approx. $150^{\circ} \mathrm{C}$ are available [25] as well, but are not used in communication cables.

A fire-resistant fiber optic cable is a single-use product. Its structure is destroyed during a fire due to:

- burning or charring of its jacket or sheath,

- melting or disintegration of glass or basalt-based strength members,

- decomposition (carbonization) of fiber coatings, buffer tubes, filling gels, etc.

Temporary fire resistance is achieved by wrapping the cable core and/or buffer tubes in refractory tapes made of synthetic fluorphlogopite mica with a silicone binder. Fluorphlogopite has the melting point of $1387^{\circ} \mathrm{C}$, is nonflammable and serves as a barrier to fire, while simultaneously preventing rapid passage of gases. Two examples of fire-resistant cables are shown in Figs. 1 and 2.

High degree of fire- and high temperature resistance is exhibited by mineral insulated (MI) electric cables, where copper or nickel-clad copper wires are surrounded by insulation made of compressed magnesium oxide powder, and are tightly encased in a metallic sheath made of copper, stainless steel or heat-resistant alloy, such as Inconel 825. Basic versions of MI cables contain no flammable materials and some of their special variants may resist a $1000^{\circ} \mathrm{C}$ fire for 3 hours or more, retaining circuit integrity. However, MI cables are expensive and are characterized by poor bending tolerance. Their mineral insulation easily absorbs moisture,

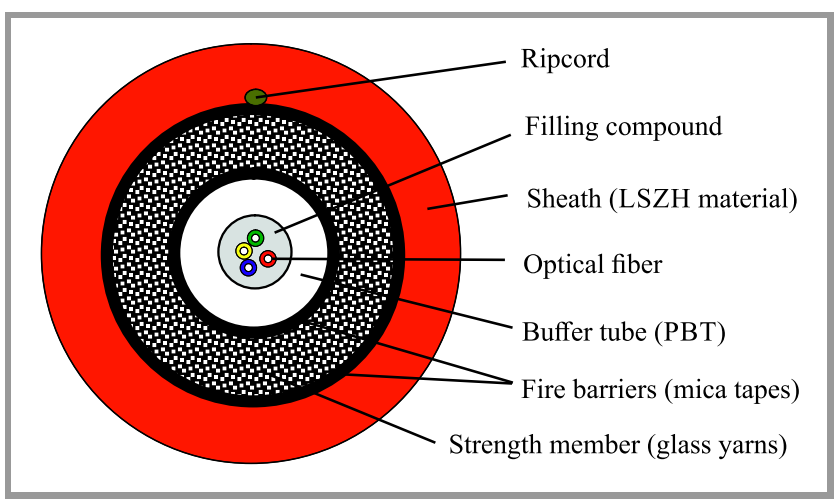

Fig. 1. Dielectric flexible fire resistant cable with a central loose tube - Technokabel FOC-2-SLT-HFFR 4G50, outer diameter $7.8 \mathrm{~mm} \mathrm{[26].}$

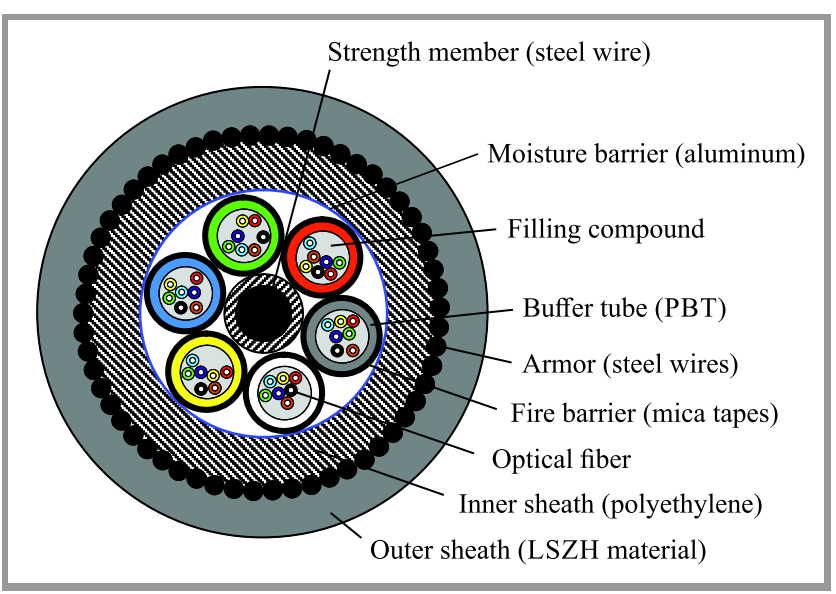

Fig. 2. Armored fire-resistant cable with stranded buffer tubes FiberTek FTSF-FLTFMAPSZ (FR), outer diameter 19.8 mm [27].

and cable termination is rather labor-intensive. Additionally, the design and, in particular, the technology relied upon to manufacture MI cables (involving high pressure extrusion and drawing) are not suitable for fragile optical fibers.

\subsection{Optical Fibers in Indoor Cables}

Cables for indoor networks incorporate standardized telecom fibers:

- graded-index multimode with 50/125 $\mu \mathrm{m}$ diameter, type OM2, OM3, OM4 or OM5 [28];

- single-mode designated as ITU-T G.652.B/D [29] and G.657.A1/2 [30]. The equivalent IEC designations are B-652 and B-657.A1/A2 [31]. ISO designations of such fibers are OS1, OS1a, or OS2 [32]. However, the technical specifications are not identical.

Multimode fibers of OM2 or OM3 type are most widely employed in emergency and security systems with relatively low bit rates. More advanced (and expensive) OM4 and OM5 multimode fibers are used in high-speed data links, 
particularly in data centers, which normally do not need to operate during a fire.

The cheapest single mode fibers (requiring, however, costly active devices) are used typically in the "vertical" sections of structural cabling carrying traffic between floors, and in links to public networks. Several of them are required to continue operating in the event of a fire, carrying emergency traffic.

\section{Testing of Fire-resistant Cables}

The examples of fire tests presented in Subsections 3.1 and 3.2 are of relatively low and high severity, respectively. The test defined in the German DIN 4102-12 standard is a "system test" covering both the cable itself and the installation hardware.

\subsection{EN 50200 Fire Test}

EN 50200 [19] simulates the effects of fire using a short length of a straight cable attached to a wall made of lightweight, refractory material. The cable subjected to the test is bent upwards at both ends of the hot zone, in line with the minimum static bending radius declared in the product's specification sheet. The entire length of the cable subjected to fire is $0.8-1.0 \mathrm{~m}$. A constant temperature of $842^{\circ} \mathrm{C}$ is generated by a $0.5 \mathrm{~m}$ long gas burner fed by a mixture of propane and air. Additionally, the vertical support holding the cable is subjected to a mechanical shock produced, every 5 minutes, by a steel rod hammer, in order to verify its mechanical integrity. The strength members in most flexible fire-resistant cables made of S-glass or Eglass yarns survive this test without melting, protecting the optical fibers inside.

The fire resistance class depends on how long the attenuation of fibers in the cable remains within the limits prescribed in EN 50582 [22]. The EN 50575 standard [20] provides for the following fire resistance classes:

- PH 15: over 15 min,

- PH 30: over $30 \mathrm{~min}$,

- PH 60: over $60 \mathrm{~min}$,

- PH 90: over $90 \mathrm{~min}$,

- PH 120: over 120 min.

An optional test involves heating the cable for 30 min while simultaneously sprinkling it with cold water for the last $15 \mathrm{~min}$, in order to simulate the operation of sprinklers in a building.

\subsection{DIN 4102-12 Fire Test}

DIN 4102-12 simulates the operation of cables passing through a room affected by a large fire. The cables undergoing the test (their number often exceeds 100) are placed on steel racks below the ceiling or are fastened to the ceiling with clips, and are then bent at the entry to the test chamber made of refractory cinder blocks, in a manner typical of a real-world installation. All cable entry holes are sealed with fire resistant mortar. The minimum length of the test chamber is $3 \mathrm{~m}$, and the cable may pass through the chamber many times to increase its length exposed to fire.

The interior of the test chamber is heated by multiple propane burners located in the lower part of the room, causing the temperature to rise in the manner shown in Fig. 3 and to exceed, $1000^{\circ} \mathrm{C}$ after $90 \mathrm{~min}$. This is the "standard" or "cellulosic" temperature curve for a fire where burning cellulose-based materials (wood, plywood, paper, cardboard, cotton, etc.) are the heat source, with the formula defined in the ISO 834-1 standard [33]:

$$
T=T_{0}+345 \log (8 t+1),
$$

where $T$ is temperature $\left[{ }^{\circ} \mathrm{C}\right], T_{0}$ - initial temperature $\left[{ }^{\circ} \mathrm{C}\right]$, and $t$ - time elapsed from the start of test [min]. The ISO curve is defined for the period of up to $180 \mathrm{~min}$, but cable tests are usually shorter.

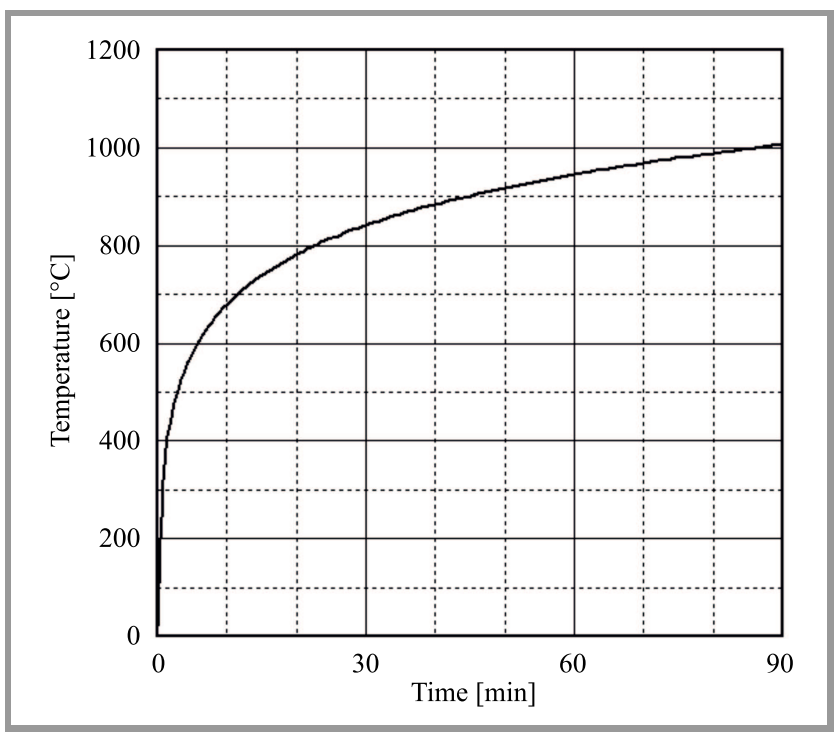

Fig. 3. Temperature vs. time during a 90-minute DIN 4102-12 fire test [21], [33].

The peak temperature is high enough to melt E-glass yarns in cables, so whether the cable will be able to retain its shape and integrity depends on the fire barrier and steel armor used (if present). Strength members made of basalt yarns do not melt, but become brittle and prone to disintegrating.

The fire resistance classification depends on length of time during which the increase of attenuation of optical fibers in the cable remains within EN 50582 limits. Three classes are distinguished: E30, E60 and E90, corresponding to the minimum cable survival time expressed in minutes.

DIN 4102-12 provides for a test covering a combination of cables and their supporting hardware. The latter determines 


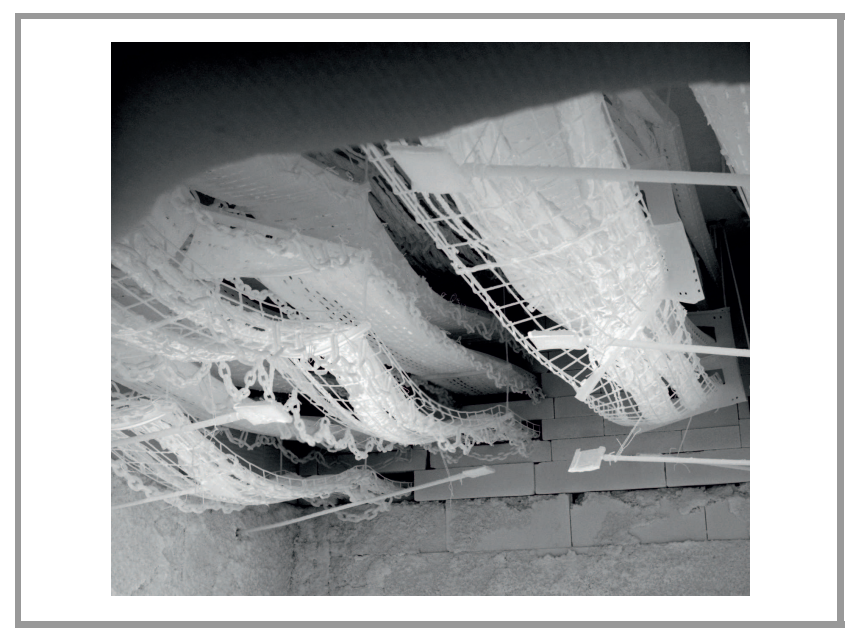

Fig. 4. Interior of a test chamber $25 \mathrm{~min}$ after commencing the DIN $4102-12$ test. Temperature equals approximately $820^{\circ} \mathrm{C}$. The sagging of cable trays is already considerable. The photograph was taken at the FIRES test lab in Batizovce, Slovakia, in 2019. Photo courtesy of Krzysztof Borzycki.

the sagging of the cable during the test (Fig. 4), affecting the overall results.

\subsection{Test Requirements for Optical Fibers}

The fire test pass criterion defined in EN 50582 [22] is based on the maximum increase of attenuation of optical fibers in the cable under test:

- for single-mode fibers: $\leq 1 \mathrm{~dB} / \mathrm{m}$ at $1550 \mathrm{~nm}$ wavelength,

- for multimode fibers: $\leq 2 \mathrm{~dB} / \mathrm{m}$ at $1300 \mathrm{~nm}$ wavelength.

Such limits assume that the length of the cable affected by fire is short, up to $5 \mathrm{~m}$, as the $3-15 \mathrm{~dB}$ reserve in the attenuation budget of a fiber optic link is usually close to this range.

\section{High Temperature Testing of Optical Fibers}

The samples of single mode and 50/125 $\mu \mathrm{m}$ graded index multimode fibers (OM2) in a $250 \mathrm{\mu m}$ primary protective coating were heated in a purpose-built electric tube oven made by a Warsaw-based Termtech company. The oven has a $1 \mathrm{~m}$ long straight tube made of alumina-rich ceramics, with a $15 \mathrm{~mm}$ hole. The fiber under test was protected against scratching and contamination by a $5 / 7 \mathrm{~mm}$ fused silica tube.

The tube was open at the ends enabling the products of the decomposition process and then of the burning of the remaining carbon (soot) to vent. This means that the conditions inside a cable are not reconstructed faithfully, as the mica fire barrier and molten glass yarns block oxygen access, thus preventing the carbon residues from burning. However, the setup (Fig. 5) was helpful in investigating incandescence and thermal deterioration of optical fibers.

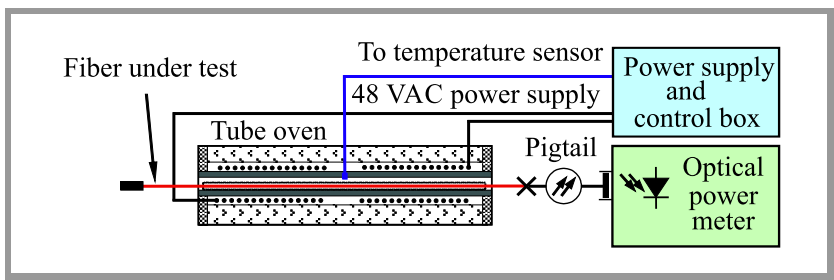

Fig. 5. Setup for measuring thermal emissions of the fiber. To measure the spectra, an optical spectrum analyzer was used instead of a power meter, and for attenuation measurements, a second pigtail and a source with the Fabry-Perot laser were added on the left-hand side instead of light-tight termination.

Test program provided for the measurements of the following:

- power and spectra of fiber thermal emissions (incandescence) vs. temperature,

- fiber attenuation vs. temperature (tests run separately due to the different setups required),

- fiber degradation after heating to $1000^{\circ} \mathrm{C}$ for up to $4 \mathrm{~h}$.

In the course of the experiments, the fiber was first heated to $400^{\circ} \mathrm{C}$, and then to $1000^{\circ} \mathrm{C}$ in $50^{\circ} \mathrm{C}$ increments. One step included an $8-10$ minute heating phase and a phase in which the temperature was kept constant for at least $5 \mathrm{~min}$. The total duration was $15 \mathrm{~min}$.

The experiments involving loose tubes with fibers placed in sealed protective tubes are planned in the future, in order to simulate conditions inside the cable during a fire.

Optical power was measured using the Agilent HP8153A optical multimeter with the HP81532A plug-in module equipped with an InGaAs 800-1700 nm photodetector, calibrated for the wavelength of $1300 \mathrm{~nm}$.

Spectra measurements take $15-25 \mathrm{~min}$ to complete due to weak signals and were performed at 800,900 and $1000^{\circ} \mathrm{C}$ with Yokogawa AQ-6315B spectrum analyzer in the 700$1700 \mathrm{~nm}$ range. Incandescence of "OH-free" single mode fibers was too weak to acquire spectrum data even at $1000^{\circ} \mathrm{C}$. Tests on some fiber samples were repeated in order to measure thermal emissions at $400-700^{\circ} \mathrm{C}$, when the results are not affected by the decomposition and burning of fiber coating and by changes in emission power and spectrum after a longer (1-4 h) heating phase, usually up to $1000^{\circ} \mathrm{C}$.

Repetition of the test did not reflect the conditions prevalent inside a fire-resistant cable, but provided some useful data for other high temperature applications in which telecom fibers are used, e.g. fiber sensors.

The following uncertainties affecting power and attenuation measurements were identified: 
- Emission power (Figs. 6, 8, and 13): $0.5 \mathrm{~dB}$ for power values higher than $-80 \mathrm{dBm}$. At lower values, the uncertainty increases due to the ingress of stray light into connectors (darkroom conditions were required for most experiments) and due to a periodic variation of power caused by on/off cycling of the oven's heater and by the temperature of the fiber under test, reaching approximately $1.5 \mathrm{~dB}$ at $-95 \mathrm{dBm}$, despite averaging;

- Fiber loss (Figs. 7 and 20): $0.02 \mathrm{~dB}$ and $0.02 \mathrm{~dB} / \mathrm{m}$ for $1 \mathrm{~m}$ samples.

Additionally, an attempt to investigate mechanisms of fiber deterioration after exposure to high temperatures, specifically distribution of light scattering defects and their appearance, was made as well - see Subsection 6.2.

\section{Test Results of OH-free Single Mode Fibers}

Two examples of cable fibers were tested:

- OFS AllWave Plus (G.652.D standard) [34] produced in 2019 ,

- OFS AllWave FLEX Plus (G.657.A2) [35] produced in 2018.

\subsection{Thermal Radiation}

The results obtained for both fibers are shown in Fig. 6. Radiation was too weak to acquire spectra.

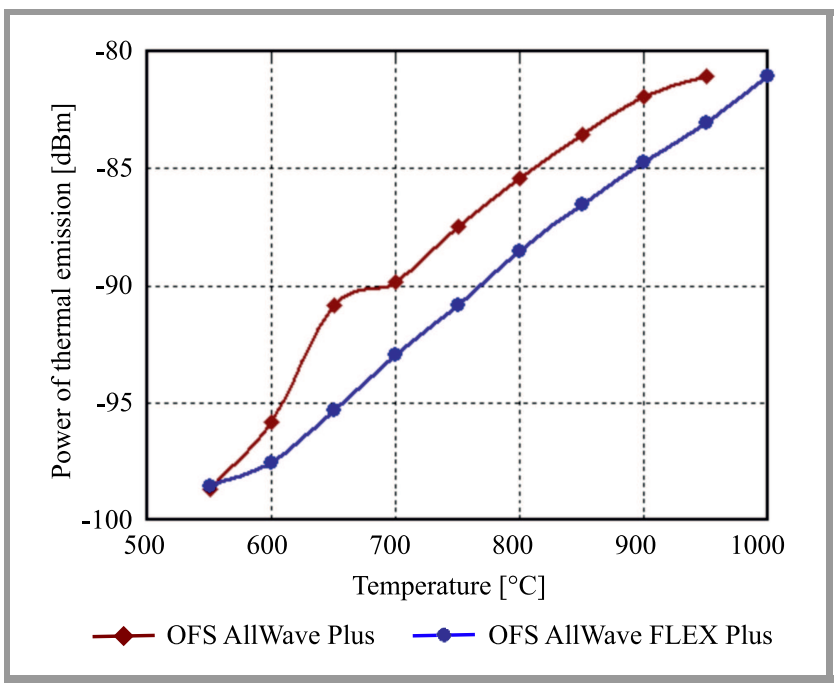

Fig. 6. Power of thermal emission vs. temperature for $\mathrm{OH}-$ free single mode fibers. Values below $-90 \mathrm{dBm}$ are affected by considerable uncertainty for reasons indicated in Section 4.

The OFS AllWave Plus fiber failed when the temperature exceeded $960^{\circ} \mathrm{C}$. The emitted power increased 1000 times in approx. $2 \mathrm{~min}$, and was slowly rising afterwards, as long as the fiber was kept at $1000^{\circ} \mathrm{C}$. The radiation spectrum indicated the coupling of radiation emitted by the hot ceramic tube of the oven. The sample lost optical continuity, but did not break. The OFS AllWave Plus fiber did not fail during the same test performed on 3 different samples. A microscope inspection revealed that some of the fiber failures were caused by contact with pieces of mineral wool fibers from the thermal insulation of the furnace.

The temporary increase of emission power at 600 and $650^{\circ} \mathrm{C}$ observed in the AllWave Plus fiber was a result of strong incandescence of black carbon soot left after decomposition of the coating materials. Some of this radiation was coupled into the fiber's core. This carbon was burned out at temperatures exceeding $700^{\circ} \mathrm{C}$. A negligible increase in power while testing the AllWave FLEX Plus "bending insensitive" fiber may be explained by its strong light guidance and weak coupling of external radiation.

\subsection{Change of Attenuation}

The results shown in Fig. 7 are for the OFS AllWave FLEX Plus fiber. The sample was heated twice. The first test involved measurements at $1304 \mathrm{~nm}$ and $1000^{\circ} \mathrm{C}$ for $40 \mathrm{~min}$, while the other at $1552.8 \mathrm{~nm}$.

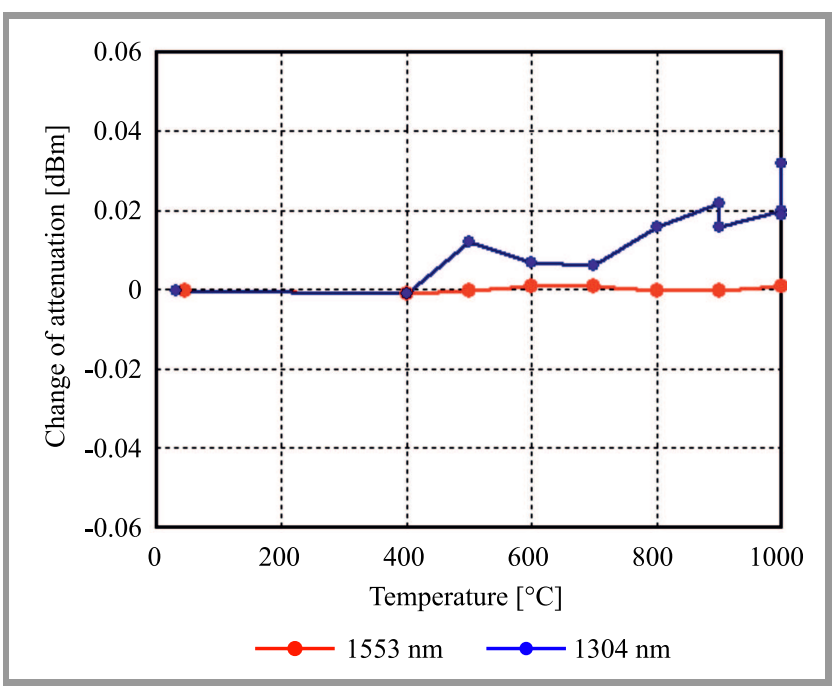

Fig. 7. Change of attenuation with temperature for OFS AllWave FLEX Plus fiber.

During the first test, the fiber coating first shrank because of decomposition and carbonization at approx. $400-500^{\circ} \mathrm{C}$, which most likely caused the fiber to bend in a wave-like fashion. The fiber undergoing the test was fixed using small weights attached thereto $15 \mathrm{~cm}$ away from the furnace, on both sides, meaning that some extra length could be dragged into the tube. Next, the carbon soot burned without residue at $600-700^{\circ} \mathrm{C}$, but the excessive length of the fiber could not be pushed out and it remained bent. This increased attenuation, which kept rising slowly with time at $1000^{\circ} \mathrm{C}$, potentially due to the softening of the fiber and a gradual increase in its curvature. The extrapolated rise 
of attenuation after $120 \mathrm{~min}$ was $0.06 \mathrm{~dB} / \mathrm{m}$. This corresponds to approximately $0.20 \mathrm{~dB} / \mathrm{m}$ at $1550 \mathrm{~nm}$, taking into account the typical wavelength dependence of losses caused by bending.

When the fiber was heated again, changes in attenuation at $1553 \mathrm{~nm}$ were below the measurement's uncertainty threshold, estimated at $0.02 \mathrm{~dB} / \mathrm{m}$, as there was no coating to exert forces on the glass fiber. The fiber attenuation changes that were predicted and measured were much lower than the $1 \mathrm{~dB} / \mathrm{m}$ acceptance limit set forth in EN 50582 [22], and most of this attenuation budget is available to cover the attenuation rise caused by fiber macrobending and/or crush when the cable is deformed during the fire.

During the tests performed in [1] on the Corning SMF28 single-mode fiber, the attenuation of bare fiber heated to $1100^{\circ} \mathrm{C}$ remained stable $(\leq 0.5 \mathrm{~dB} / \mathrm{m})$ for $48 \mathrm{~h}$, but at $1150^{\circ} \mathrm{C}$ it began to rise after $12 \mathrm{~h}$. The report [1] does not specify the test wavelength.

\section{Test Results for Old Single Mode Fiber}

Here, the results obtained for the Siecor SMF-1528 fiber (G.652.A) manufactured in 1993 are presented. This was an equivalent of the popular Corning SMF-28 fiber, made in Germany under license by Siecor $\mathrm{GmbH}$.

\subsection{Thermal Radiation}

The same sample was tested twice, showing some signs of decomposition and burning of the fiber coating and removal of $\mathrm{OH}$ ions from the core of the fiber (the so-called drying effect).

During the second part of the test, heating was continued up to $1000^{\circ} \mathrm{C}$ for $120 \mathrm{~min}$, with amplitude of the main

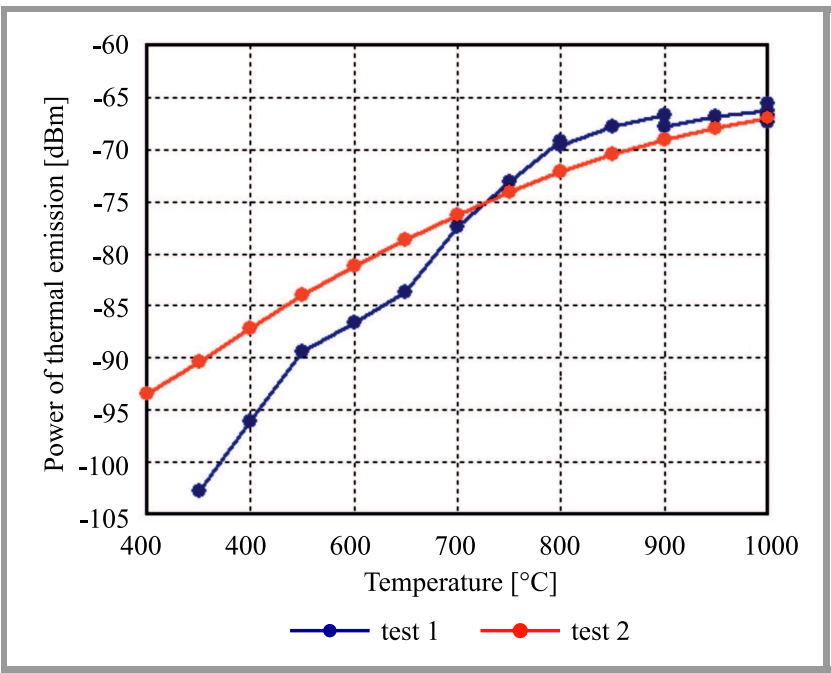

Fig. 8. Power of thermal emission vs. temperature for the Siecor SMF-1528 fiber. The values below $-90 \mathrm{dBm}$ are affected by considerable uncertainty, as described in Section 4. water peak at $1383 \mathrm{~nm}$ decreased by approx. 50\%. The first test also produced relatively few microscopic defects in the fiber, made evident by weak, distributed scattering of light injected by a $650 \mathrm{~nm}$ (red) laser, and by a considerable increase in thermal radiation power at temperatures up to $700^{\circ} \mathrm{C}$, presumably due to the coupling of radiation emitted into the fiber core by carbonized coating. The escape of water at higher temperatures reduced the aforementioned value again.

The power data obtained is presented in Fig. 8. The visible discontinuities found at 800 and $900^{\circ} \mathrm{C}$ correspond to spectral measurements, both lasting 25-30 min. At the end of the first test, the fiber was kept at $1000^{\circ} \mathrm{C}$ for $100 \mathrm{~min}$. During this time its thermal radiation decreased by $40 \%-$ see Figs. 11 and 12.

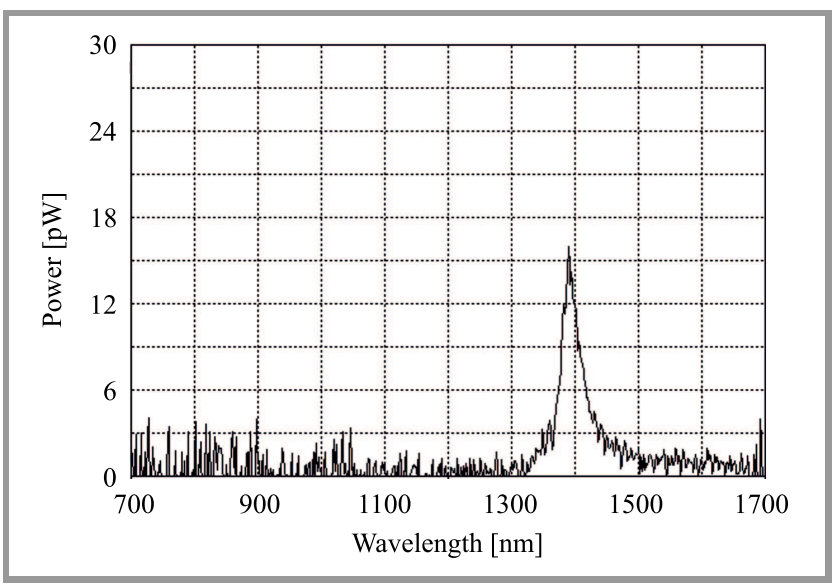

Fig. 9. Spectrum of thermal emission acquired for the Siecor SMF-1528 fiber at $800^{\circ} \mathrm{C}$. The vertical axis is optical power in each spectrum slice of width equal to the analyzer's resolution bandwidth $(10 \mathrm{~nm})$.

The radiation spectra presented in Figs. 9-12 were acquired during test 1 . The 1246, 1383, 1393, and $1407 \mathrm{~nm} \mathrm{OH}$ bands listed in Table 1 are visible despite the $10 \mathrm{~nm}$ resolution, and their relative amplitudes are in agreement. In the last spectrum shown in Fig. 12, a continuous compo-

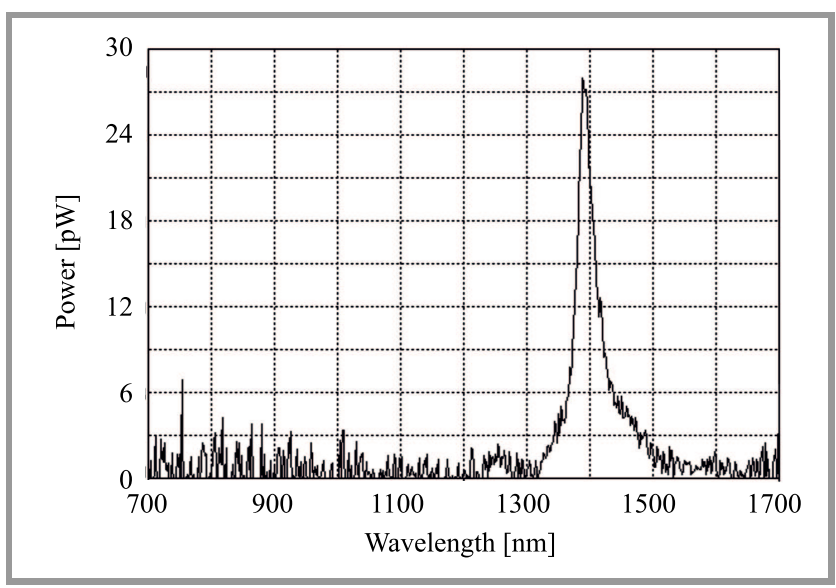

Fig. 10. Spectrum of thermal emission for the Siecor SMF-1528 fiber at $900^{\circ} \mathrm{C}$. 
nent specific to the incandescence of ceramics appears. It was coupled to the fiber's core by the rising number of defects in the glass - see Subsection 6.2.

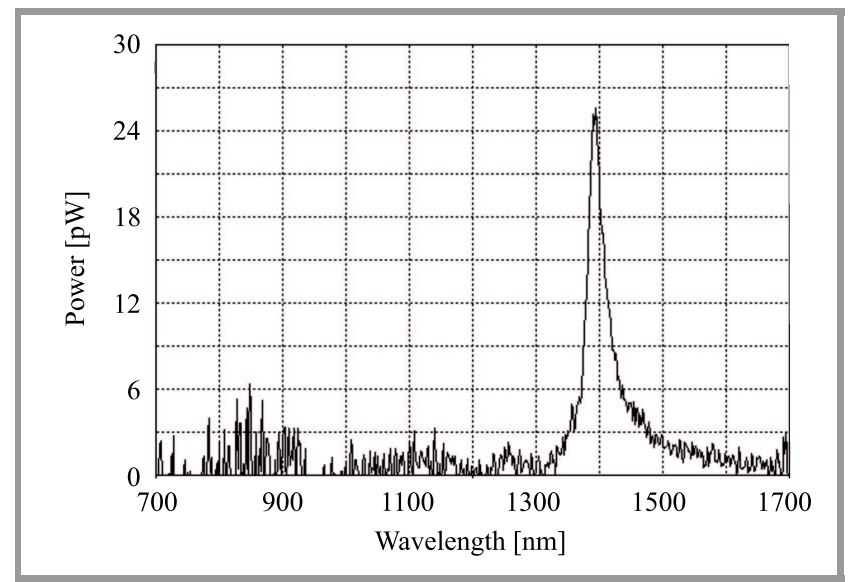

Fig. 11. Spectrum of thermal emission for the Siecor SMF-1528 fiber at $1000^{\circ} \mathrm{C}$.

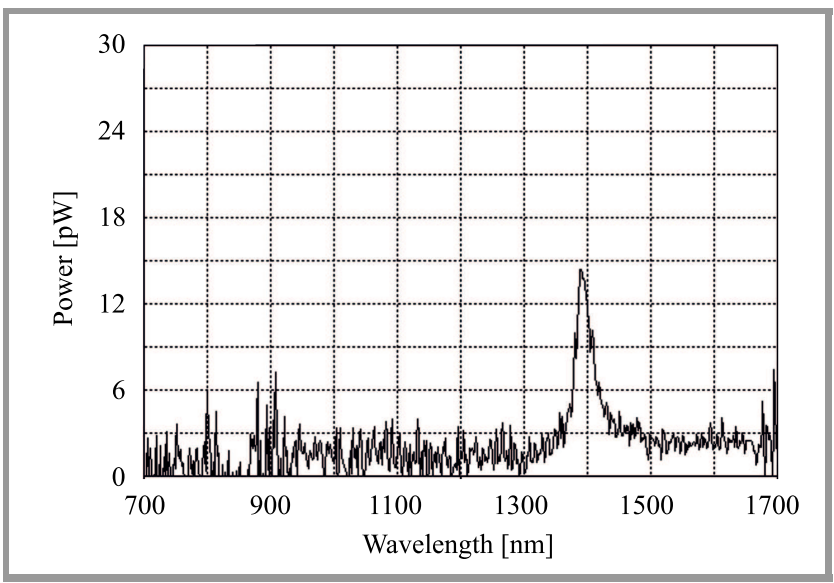

Fig. 12. Spectrum of thermal emission for the Siecor SMF-1528 fiber after 100 minutes at $1000^{\circ} \mathrm{C}$.

\subsection{Light Scattering and Defects}

Uneven and randomly distributed scattering of red light from a $650 \mathrm{~nm}$ laser was observed in fiber samples heated, over the period of several hours, to $900-1000^{\circ} \mathrm{C}$, but never in adjacent sections of the same fiber not exposed to high temperatures.

An example of longitudinal distribution of light scattering intensity in a heat-degraded Siecor SMF-1528 fiber is shown in Fig. 13. This was the sample tested in Subsection 6.1 , but part of it was damaged during handling. Interestingly, there is no full correlation between intensity of lateral scattering and backscattering.

Observations made with the use of an optical microscope showed that the locations scattering visible light launched into the fiber sample turned out to be small spots and long wavy lines formed on the fiber's surface, from which cracks

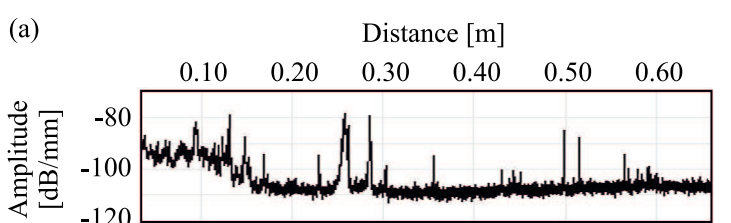

(b)

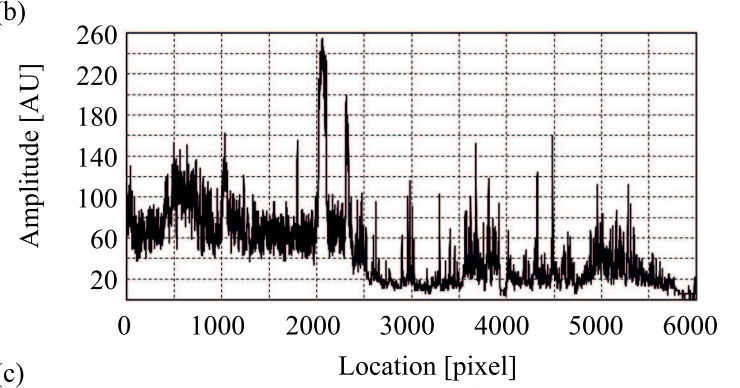

(c)

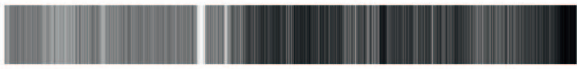

Fig. 13. Intensity of $650 \mathrm{~nm}$ light scattered laterally along a $62 \mathrm{~cm}$ section of the Siecor SMF-1528 single-mode fiber heated in free air to $900-1000^{\circ} \mathrm{C}$ for 4.5 hours and observed at room temperature. The image was obtained by averaging all pixels in each column in a photo of the fiber (c) and corresponding distribution of luminosity (b). The top graph is an OTDR trace acquired at $1550 \mathrm{~nm}$ with the OTDR - Luna Technologies OBR 4600 millimeter-resolution reflectometer.

usually extended into the cladding at different angles relative to the surface (Fig. 4). After cooling to room temperature, the fiber was very brittle and could not be cleaned without breaking. No defects were observed in the core.

The physical degradation of a fused silica fiber subjected to high temperatures may be described in the following way. At temperatures above $850-900^{\circ} \mathrm{C}$, fused (glassy) silica is slowly converted into its crystalline form known as cristoballite, which has higher specific gravity of 2.35 vs. 2.20, and a refractive index of 1.485 vs. 1.458 at $589.3 \mathrm{~nm}\left(\mathrm{n}_{\mathrm{D}}\right)$ wavelength. The crystallization of fused silica is intensified by the presence of water vapor in the gas mixture in the glass fiber's outline [1]. Water vapor is a product of thermal decomposition of oxygen-containing polymers, including poly(butylene terephtalate) [36], the most popular material of which loose tubes in fiber optic cables are made, and acrylates [37], of which primary coatings of optical fibers are made. It is also a product of burning of virtually all polymers (e.g. jacket of cables) and wood. Rose and Bruno [38] presented a short description of this process and listed the literature focusing on the subject.

The crystallization causes a localized strain after the loss of approximately $6 \%$ of the material's volume. This strain can initiate cracks penetrating the fiber cladding. A crack in the vicinity of or penetrating the core will disturb light guidance by deflecting some light away, thus resulting in scattering. Minuscule grains of cristoballite embedded in fused silica will cause omnidirectional scattering of both guided light - when inclusions are in the core, and external light - when inclusions are in the cladding. Defects 
of the first type produce backscattering and loss of guided light from the fiber core, increasing its attenuation. Defects of the other type redirect some of the external thermal radiation to the fiber's acceptance cone.

The size of crystal grains observed on the surface of moderately heat-degraded fibers, after heating to $1000^{\circ} \mathrm{C}$ for several hours, as reported in literature [1], [38]-[40] usually equals $3-30 \mu \mathrm{m}$, which is in agreement with our observations (Fig. 14). Cracks in fiber cladding after heating to $850^{\circ} \mathrm{C}$ for more than 8 hours, or to a higher temperature, were reported by Rose [39], who concluded that a strong rise in attenuation of the fiber kept at $1100^{\circ} \mathrm{C}$ is explained by the formation of microcrystals - not only on the surface, but also inside the fiber core. The fiber tested had the same design and dimensions as SMF-1528 (type of fiber was not indicated). Shikama et al. [40] observed "spots" on the fiber surface only, which were approximately $3 \times$ larger than those showed in Fig. 14, but no cracks after heating to $1000^{\circ} \mathrm{C}$ for 15 hours. The fiber tested had a cladding made of fluorine-doped fused silica instead of pure silica used in SMF-1528.

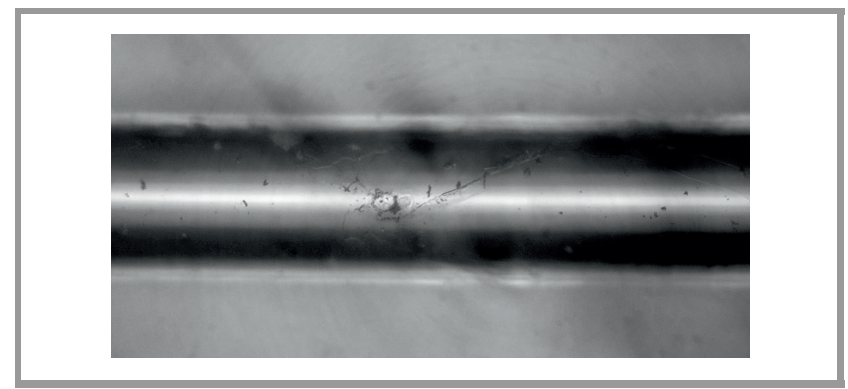

Fig. 14. A light-scattering location in fiber from Fig. 13, at OTDR distance about $45 \mathrm{~cm}$, seen under microscope. The righthand part of defect is a long crack extending into fiber cladding.

The entry of broadband thermal radiation from the hot surroundings into the fiber has been reported back in the days, together with an observation that fiber deterioration responsible for this phenomenon is enhanced by defects produced by gamma radiation from a ${ }^{60} \mathrm{Co}$ source [2], [40]. Both papers did not elaborate on any optical coupling mechanisms.

\section{Test Results for 50/125 $\mu \mathrm{m} \mathrm{OM} 2$ Multimode Fibers}

\subsection{Thermal Emission vs. Temperature}

The fiber under test was OFS $50 \mu \mathrm{m}$ graded-index OM2 [41], manufactured in 2019. The sample was tested four times, with the maximum temperature during test 1 set at $900^{\circ} \mathrm{C}$ to avoid a rapid fiber failure observed during several other experiments. The results are similar to those obtained for the old single mode fiber, except for stronger radiation.

Figure 15 shows power measurement data, while the spectra acquired are presented in Figs. 16-19. After an initial

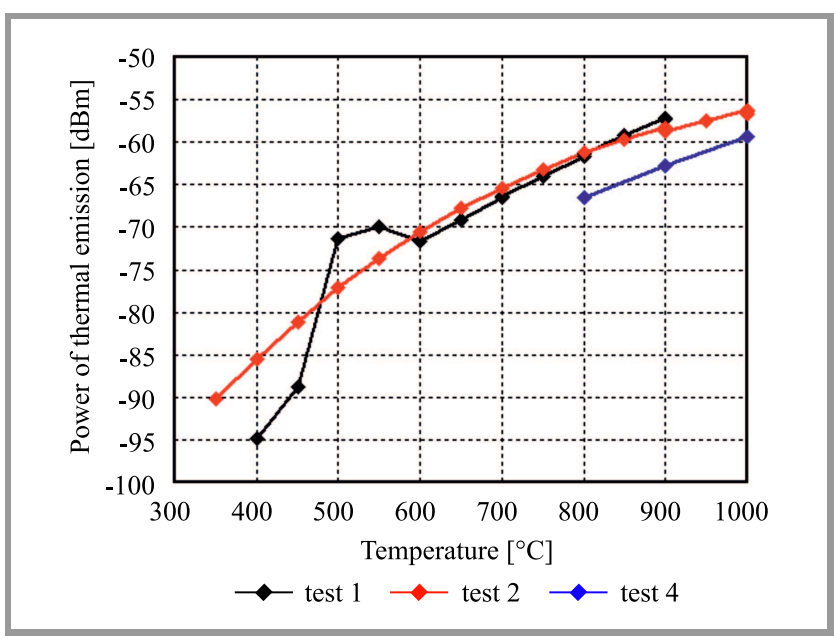

Fig. 15. Power of thermal emission vs. temperature for the OFS MM50 fiber. Values below $-90 \mathrm{dBm}$ are affected by measurement uncertainty.

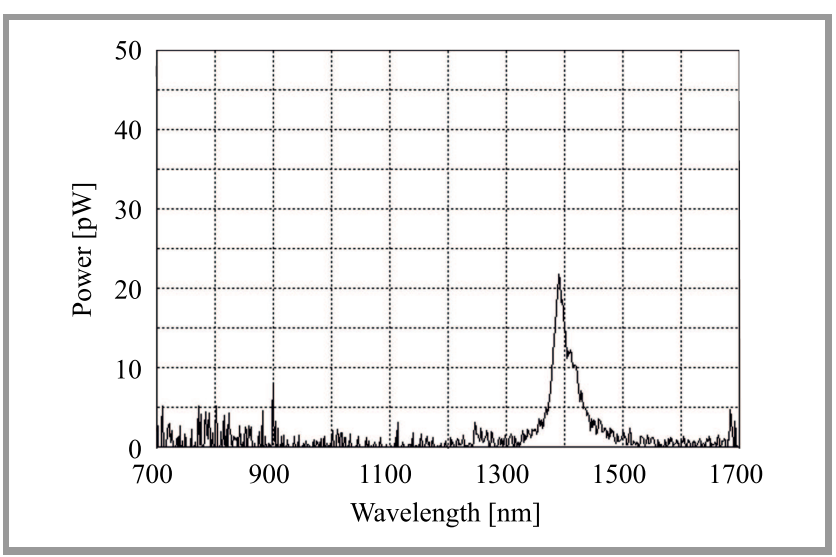

Fig. 16. Spectrum of thermal emission for the OFS MM50 fiber at $800^{\circ} \mathrm{C}$ in test 1.

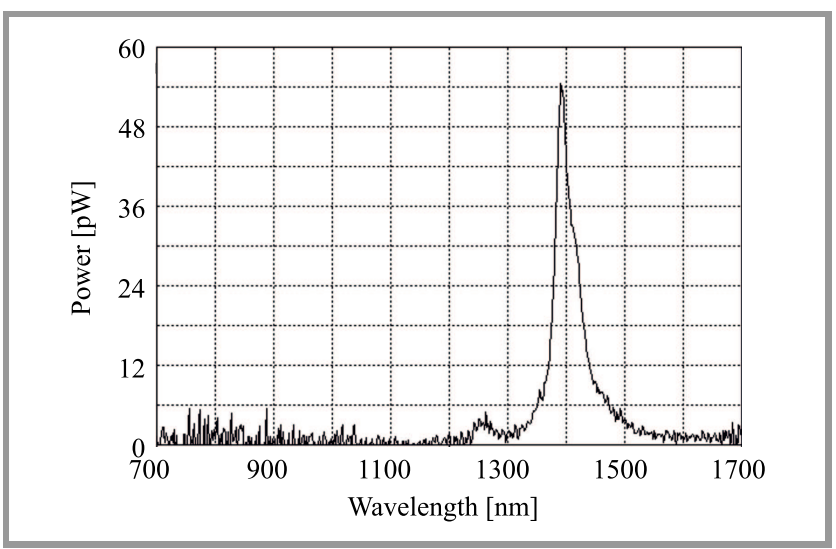

Fig. 17. Spectrum of thermal emission for the OFS MM50 fiber at $900^{\circ} \mathrm{C}$ in test 1 .

rise in emission intensity (Figs. 16 and 17), a further temperature increases to $800-1000^{\circ} \mathrm{C}$ for 4 hours triggered the water escape and reduced the amplitude of $\mathrm{OH}$ emission peaks by approx. $80 \%(7 \mathrm{~dB})$. As shown in Fig. 12, the last two spectra include a broadband component. This in- 


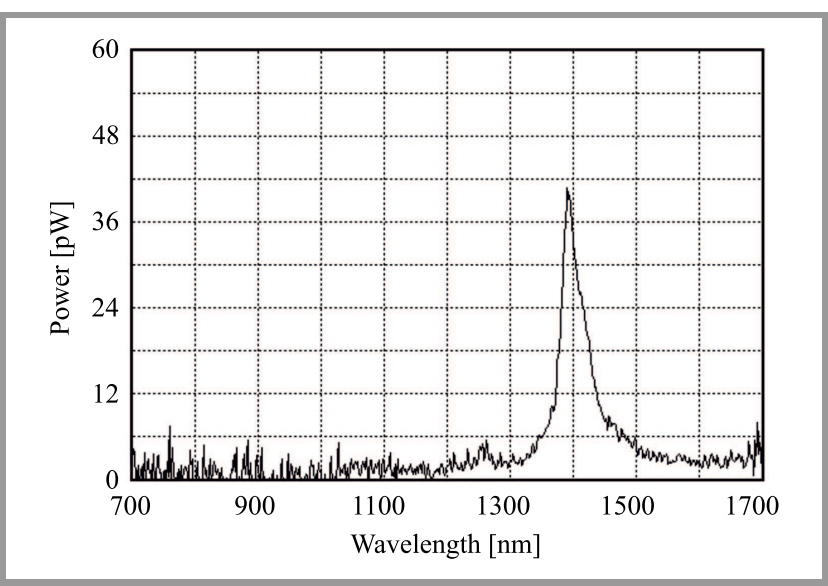

Fig. 18. Spectrum of thermal emission for the OFS MM50 fiber at $1000^{\circ} \mathrm{C}$ in test 2 .

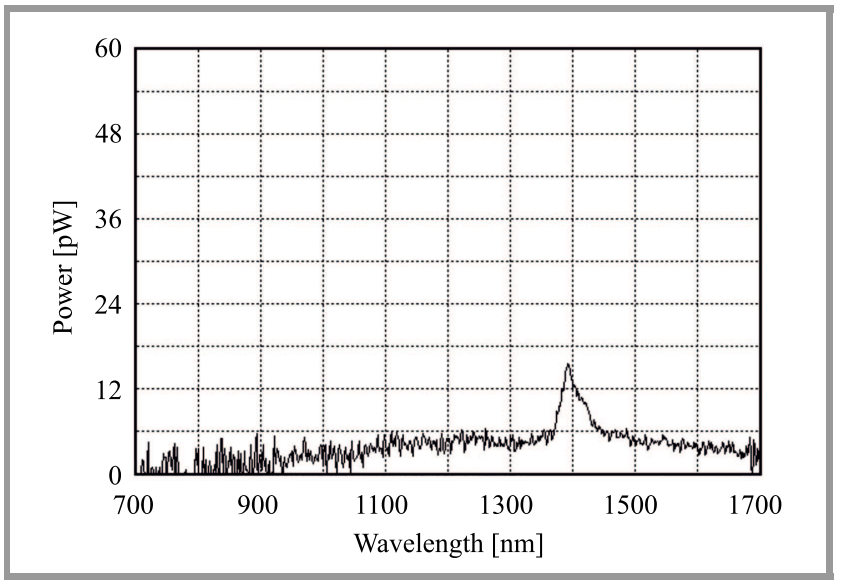

Fig. 19. Spectrum of thermal emission for the OFS MM50 fiber at $1000^{\circ} \mathrm{C}$ in test 4 , after 4 hours of heating to $800-1000^{\circ} \mathrm{C}$.

dicates the coupling, into the fiber, of radiation emitted by the glowing ceramic tube of the oven. Interestingly, none of the multimode fibers have showed any detectable emissions at $945 \mathrm{~nm}$ (Table 1).

\subsection{Change of Attenuation vs. Temperature}

The tested fiber was the Fujikura FutureGuide-MM50 [42] manufactured 2019. The sample was heated twice: the first test involved measurements performed at $1304 \mathrm{~nm}$, while the other at $842 \mathrm{~nm}$.

The changes in attenuation observed (Fig. 20) did not exceed $0.025 \mathrm{~dB} / \mathrm{m}$. As in the single mode fiber, higher values appeared during the first test, when the fiber coating was carbonized and burned. During this experiment, we experienced random variations of indicated attenuation due to imperfect coupling between the Fabry-Perot laser sources and the fiber tested, and due to reflections in the fiber optic connectors back into the laser.

During tests performed on the 50/125 $\mu \mathrm{m}$ multimode fiber of a similar design [1], the attenuation of fiber heated in the air to $1100^{\circ} \mathrm{C}$ remained fairly stable $(\leq 1 \mathrm{~dB} / \mathrm{m})$ for over $300 \mathrm{~h}$, but at $1200^{\circ} \mathrm{C}$, it began to rise fast after less than

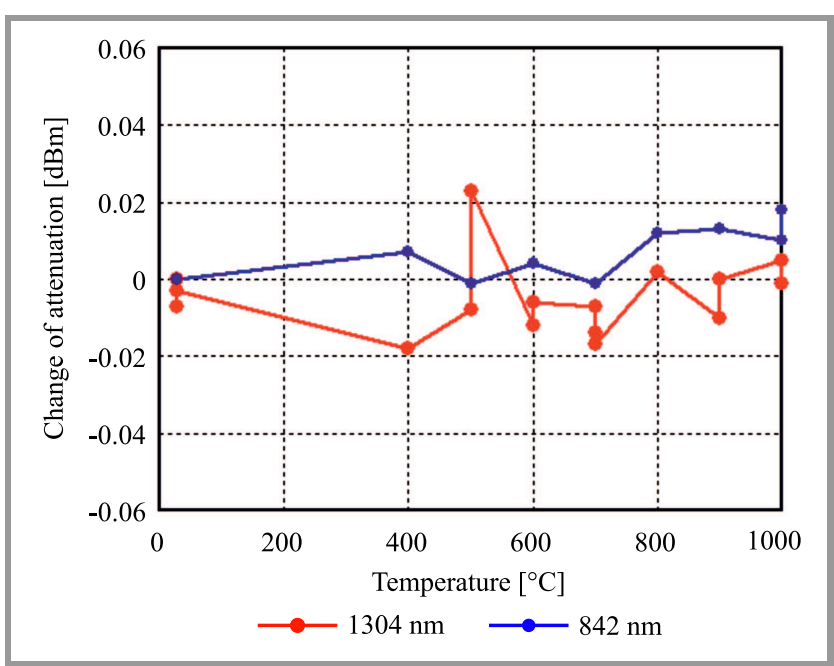

Fig. 20. Attenuation vs. temperature for the Fujikura FutureGuide-MM50 fiber.

$20 \mathrm{~h}$ and the fiber essentially lost its optical continuity after $40 \mathrm{~h}$. The report does not indicate clearly the wavelength at which the attenuation was monitored - most likely it was $1064 \mathrm{~nm}$.

\section{Overview of Spurious Radiation in Hot Silica Fibers}

This section describes the characteristics of spurious radiation appearing in telecom type fused silica fibers subjected to a fire. The data presented comes from literature and from the experiments conducted. Other cable families, e.g. specialty fibers with a pure silica core and fluorine-doped cladding, intended for high temperature and radiation environments, may behave differently [1].

\subsection{Thermal Radiation Generated in Fiber}

Thermal emission of radiation in an optical fiber is proportional to the intensity of radiation absorption at a given wavelength, but not to scattering. The peaks correspond to absorption bands associated with the presence of $\mathrm{OH}$ ions in the glass constituting the fiber core, and intensity of emission peaks is proportional to the added attenuation in $\mathrm{OH}$ absorption bands, also known as "water peaks". This phenomenon was reported thanks to research on high temperature fiber sensors [1], [2], but the tests were performed mostly on specialty fibers with a high $\mathrm{OH}$ content.

Peak wavelengths with relative absorption (and thus the expected emission) intensities of $\mathrm{OH}$ absorption bands between 700 and $1700 \mathrm{~nm}$ calculated using the data published in [43] are presented in Table 1. Intensity of $\mathrm{OH}$ emission at wavelengths close to $1390 \mathrm{~nm}$ rises along with temperature, in accordance with the Arrhenius formula and $1.13 \mathrm{eV}$ activation energy, as reported by Shikama et al. [40]. This dependence is useful for temperature sensing with a short piece of a special high-OH fiber. 
Table 1

$\mathrm{OH}$ absorption bands in fused silica

\begin{tabular}{|c|c|}
\hline Peak wavelength [nm] & Relative intensity $[\mathrm{dB}]$ \\
\hline 724 & -29.1 \\
\hline 825 & -42.2 \\
\hline 878 & -28.9 \\
\hline 943 & -16.1 \\
\hline 1139 & -29.5 \\
\hline 1246 & -13.7 \\
\hline 1383 & 0.0 \\
\hline 1393 & -2.4 \\
\hline 1407 & -7.0 \\
\hline
\end{tabular}

The increase of attenuation in the three strongest adjacent OH absorption bands: $1383 \mathrm{~nm}, 1393 \mathrm{~nm}$ and $1407 \mathrm{~nm}$ in old single-mode fibers conforming to the ITU-T G.652.A standard [29] may reach $2 \mathrm{~dB} / \mathrm{km}$ at $20^{\circ} \mathrm{C}$. In "low water peak" single-mode fibers conforming to G.652.D or G.657.A/B [30] standards, values of up to $0.05 \mathrm{~dB} / \mathrm{km}$ are typical. All three $\mathrm{OH}$ bands are frequently combined as a single "1390 nm water peak" due to low resolution of spectral measurements. The examples of spectra are presented in Subsections 6.1 and 7.1.

Two other mechanisms, namely phonon absorption and UV absorption, noticeably contribute to the increase in attenuation at wavelengths longer than $1750 \mathrm{~nm}$ or shorter than $500 \mathrm{~nm}$, respectively. While the first type of radiation lies outside the sensitivity range of common fiber optic receivers and power meters, receivers based on $850 \mathrm{~nm}$ silicon photodiodes are somewhat sensitive to short-wave radiation of the second type.

The measurements performed by the authors in the 700$1700 \mathrm{~nm}$ range with the Yokogawa AQ-6315B optical spectrum analyzer only detected radiation peaks coinciding with the four strongest $\mathrm{OH}$ bands listed in Table 1. The probable explanation is that spectral measurements are characterized by low sensitivity. Attenuation added at the absorption peak had to exceed $0.2 \mathrm{~dB} / \mathrm{km}$ at room temperature for the corresponding emission from a $1 \mathrm{~m}$ long fiber sample at $1000^{\circ} \mathrm{C}$ to be detectable with the spectrum analyzer available.

After commercial introduction of "OH-free" or "low water peak" dispersion unshifted single mode fiber in 1999, this product was steadily increasing its market share to reach the value of $90 \%$ today. However, cheap OH-contaminated fibers are still sold and permitted under the ISO/IEC 11801 standard for structural cabling [32]. The authors expected "OH-free" fibers to exhibit weak incandescence. Pre-2000 single mode fibers contaminated with $\mathrm{OH}$ ions behave differently. Multimode fibers widely used in local area networks, data centers and indoor communication systems exhibit the strongest water peaks.

\subsection{Thermal Radiation Coupled into Fiber}

The highest level of interference is experienced when the fiber is surrounded by a carbonaceous char whose emissivity is close to 1 , as for a blackbody radiator. The wavelength corresponding to peak blackbody emission $\lambda_{\text {peak }}$ may be calculated in accordance with the Wien's displacement law:

$$
\lambda_{\text {peak }}=\frac{b}{T+273.16}
$$

where $b$ is the Wien's displacement constant of $2.898 \times$ $10^{-3} \mathrm{~m} \cdot \mathrm{K}$, and $T$ is the temperature $\left[{ }^{\circ} \mathrm{C}\right]$. Under fire conditions, the peak wavelengths are 2700-2277 $\mathrm{nm}$. In the spectral range relevant for fiber optic transmissions and testing, i.e. $800-1650 \mathrm{~nm}$, spectral density of blackbody thermal radiation rises with an increase in wavelength.

However, spectra of radiation emitted by char and delivered by the optical fiber to the spectrum analyzer differ from the theoretical curves - see Fig. 21. In particular, the fall of power at wavelengths close to $1390 \mathrm{~nm}$ wavelength results from high fiber attenuation at three combined $\mathrm{OH}$ absorption peaks (Table 1).

Attenuation at $1390 \mathrm{~nm}$, as tested by Rose and Bruno [38] in a single-mode fiber similar to SMF-1528, was tem-

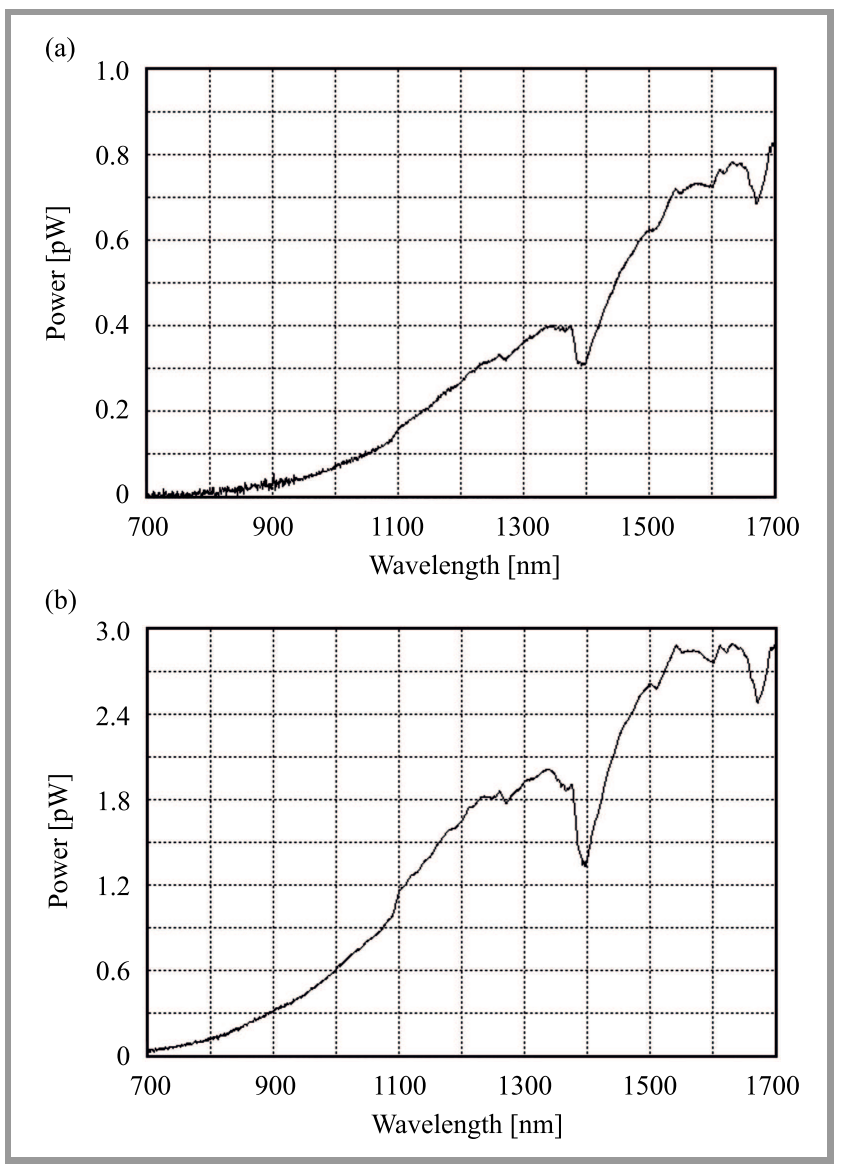

Fig. 21. Spectra of radiation emitted by carbon char left from pyrolysis of acrylate polymer the fiber-tight buffer was made of, at $800^{\circ} \mathrm{C}$ (a) and $1000^{\circ} \mathrm{C} \mathrm{(b),} \mathrm{collected} \mathrm{at} \mathrm{the} \mathrm{end} \mathrm{of} \mathrm{a} 2.5 \mathrm{~m}$ long $50 / 125 \mu \mathrm{m}$ multimode fiber, of which approx. $0.3 \mathrm{~m}$ was placed in the hot zone of the furnace. 
perature-dependent, reaching $8.5 \mathrm{~dB} / \mathrm{m}$ at $950^{\circ} \mathrm{C}$. However, the fall to $3.5 \mathrm{~dB} / \mathrm{m}$ at $1000^{\circ} \mathrm{C}$ reported there appears to be caused by the "drying" of fiber [39] - see Subsection 8.3. In our experiment, the estimated attenuation of a multimode fiber [38] for $1390 \mathrm{~nm}$ was $6.3 \mathrm{~dB} / \mathrm{m}$ at $800^{\circ} \mathrm{C}$ and $7.6 \mathrm{~dB} / \mathrm{m}$ at $1000^{\circ} \mathrm{C}$.

\subsection{Intensity of Thermal Radiation vs. Time}

The power of both kinds of thermal radiation described above varies considerably with the duration of heating, but in opposite ways.

The heating of a bare fused silica fiber to $800^{\circ} \mathrm{C}$ or more decomposes hydroxyl $(\mathrm{OH})$ ions, producing hydrogen which diffuses through the fiber cladding [39], and the OH-related emission peaks fade gradually [1], [2]. This effect reduces optical interference and is beneficial in high temperature applications of optical fibers. In the experiments we conducted, the heating of both single-mode and multimode telecom fibers with pure silica cladding to $1000^{\circ} \mathrm{C}$ for $1 \mathrm{~h}$ (the approximate duration of such an exposure during a DIN 4102-12 fire test) decreased the amplitude of emission peaks by approx. 50\%. In a depressed-clad single-mode fiber (Lycom SM-DC) with fluorine-doped inner cladding this process was slower, with the half-fading time equaling approximately $2 \mathrm{~h}$. During the tests performed by Honda et al. [2] on a pure silica core fiber with $25 \mu \mathrm{m}$ thick fluorine-doped cladding (compared to approx. $5 \mathrm{\mu m}$ in the SM-DC fiber), the half-fading time at $1000^{\circ} \mathrm{C}$ was about $80 \mathrm{~h}$. A chemical reaction between fluorine and hydrogen, slowing down the latter's diffusion through the layer of fluorine-doped silica glass, is a potential explanation here.

Such thermally induced fading of fiber incandescence has been reported recently [1], [2], [38] for several types of fused silica fibers. Additionally, it was documented that specialty fibers with high $\mathrm{OH}$ content emit considerably stronger radiation than low-OH telecom fibers [1].

Crystallization and the related cracking of fused silica at $900-1000^{\circ} \mathrm{C}$ progress steadily with time, and the power of coupled radiation rises slowly, starting from a very low initial value. This effect was reported i.e. in [2], [38], [40], but without any explanations of the physical phenomena behind the coupling of external radiation to the fiber.

In addition to slow degradation after heating for $1 \mathrm{~h}$ (and more), the authors observed several sudden and rapid failures (within 30 seconds) of fiber samples at temperatures over $900^{\circ} \mathrm{C}$. The samples began to emit powerful radiation and lost their optical continuity. The damaged sections were short (approx. $2 \mathrm{~cm}$ ), had milky-white appearance, and scattered away all light launched into the fiber. This type of fiber failure occurred only in some cases, when multiple samples were tested in the same conditions. Localized runaway crystallization reaching the fiber core, potentially initiated by surface contamination, is the presumed cause here.

Consequently, the radiation spectrum evolves during the heating (and exposure to gamma radiation, if present) - the share of broadband thermal radiation coupled from the outside increases. This is proved by the spectra measured in our experiments (Figs. 11-12, 16-19) and in [2], [38].

\subsection{Radiation Intensity vs. Fiber Type}

Power of radiation emitted by a unit of the fiber's length depends on the following:

- attenuation caused by $\mathrm{OH}$ content,

- fiber ability to collect radiation emitted omnidirectionally.

Telecom-grade single-mode fibers have a lower core diameter and numerical aperture (NA) than their multimode counterparts (OM2-OM5): 7-9 $\mu \mathrm{m}$ vs. $50 \mu \mathrm{m}$ and approx. 0.14 vs. 0.20 , respectively. Single mode fibers are characterized by a low diameter of the light-guiding core, typically equaling 7-9 $\mu \mathrm{m}$. The mode field diameter (MFD) listed in fiber data sheets is $20-40 \%$ larger due to diffraction effects, and increases with wavelength.

The power of thermal radiation generated in a unit of the fiber's length is proportional to the core area, while the portion of this emission accepted by the fiber is proportional to the square of NA. Correspondingly, the difference between thermal emission exiting equal lengths of single-mode and multimode fibers with equal $\mathrm{OH}$ content is between 1:50 and $1: 100$ or $17-20 \mathrm{~dB}$. A similar relationship may be assumed for the radiation coupled from the outside.

Values of thermal emission power measured by the authors with the InGaAs detector (sensitivity range of 800 $1700 \mathrm{~nm}$ ) are presented in Table 2. The results apply to a relatively short heating period lasting $1-2 \mathrm{~h}$.

Table 2

Power of thermal radiation from $1 \mathrm{~m}$ samples of fibers at $900^{\circ} \mathrm{C}$

\begin{tabular}{|c|c|c|}
\hline Type of fiber & Standard & $\begin{array}{c}\text { Power of thermal } \\
\text { radiation }[\mathrm{dBm}]\end{array}$ \\
\hline $\begin{array}{c}\text { Single-mode }- \\
\text { low water peak }\end{array}$ & $\begin{array}{c}\text { G.652.D, } \\
\text { G.657.A }\end{array}$ & $-85 \ldots-82$ \\
\hline $\begin{array}{c}\text { Single-mode }- \\
\text { with water peak }\end{array}$ & G.652.A & $-71 \ldots-66$ \\
\hline $\begin{array}{c}50 / 125 \mu \mathrm{m} \text { graded } \\
\text { index multimode }\end{array}$ & OM2 & $-60 \ldots-52$ \\
\hline
\end{tabular}

\subsection{Radiation Intensity vs. Fiber Length}

radiation launched into the fiber is proportional to its length being heated, the power exiting this section of the fiber is not. This is due to the rise of fiber attenuation in the fire affected zone. Under such conditions, the power of thermal radiation rises initially with length, and later saturates when the power added in each imaginary fiber section just compensates for the losses caused by high attenuation.

For the maximum attenuation values defined in EN 50582 [19]: $1 \mathrm{~dB} / \mathrm{m}$ (SM fiber) or $2 \mathrm{~dB} / \mathrm{m}$ (MM fiber), 
the saturation length is approx. $4 \mathrm{~m}$ and $2 \mathrm{~m}$, respectively. While the high level of thermally induced attenuation in the vicinity of the $1390 \mathrm{~nm}$ emission peak may shorten saturation length to much less than $1 \mathrm{~m}$ in a multimode fiber, the authors have measured the total power of up to $-37 \mathrm{dBm}$ at $950^{\circ} \mathrm{C}$ during a fire test of a 32 m multimode cable. However, this particular OM2 fiber could be easily thermally damaged during other experiments.

\section{Discussion}

The influence of high temperatures on the optical properties of telecom fibers made of fused silica has been covered in relatively few research papers with most of these focusing on fibers used for sensing in harsh environments. We failed to find a single publication (other than a few cable fire test reports) dealing with the optical phenomena in fibers inside a fire-resistant cable under fire conditions.

Results of the majority of the experiments conducted, e.g. measurements of spectra and time dependence of thermal radiation, are confirmed by data published by other authors. Alas, most of such data [1], [2], [40] is related to specialty multimode fibers with a core diameter of 50-200 $\mathrm{km}$, often with a pure silica core and fluorine-doped cladding, and with $\mathrm{OH}$ content substantially higher than in telecom fibers. The only test data for single-mode and multimode fibers of the telecom type is presented in [1]. This paper also includes formulas and parameters concerning fiber "drying", fading of $\mathrm{OH}$ thermal emission with time, as well as temperature dependence of the power of emission. However, article [40] a different activation energy: $1.13 \mathrm{eV}$ vs. $0.76-0.86 \mathrm{eV}$.

The available data on defects caused by fiber heating and on the associated optical effects, such as light scattering and coupling into fiber, is scarce, but is generally in alignment with our findings. Fiber cracking after heating to 1000$1100^{\circ} \mathrm{C}$ has been reported recently [1], [39], while Honda et al. [2] and Shikama et al. [40] detected the coupling of external radiation emitted by a hot ceramic tube of the oven, the intensity of which rose with the duration of exposure to high temperature (up to $100 \mathrm{~h}$ at $1000^{\circ} \mathrm{C}$ ) and with the dose of $\gamma$ radiation received by the fiber during the test. Despite the fact that the type of fiber tested was different: 200/250 $\mu \mathrm{m}$ [2] or $125 \mu \mathrm{m}$ [40] step-index multimode with a pure silica core and fluorine-doped cladding, the radiation spectra were essentially identical to ours. However, intensity of the main radiation peak at $1390 \mathrm{~nm}$ rose steadily with time (no fading), and the authors of paper [2] suggested that $\gamma$ irradiation damage was the only source of light-coupling defects.

This hypothesis is contradicted by measurements of emission spectra from a fiber heated without $\gamma$ irradiation, published in [2], [40], where emergence of broadband background radiation is visible - although it was much stronger with $\gamma$ irradiation.

The literature and the standards fail to address the detrimental effects that optical interference emerging in hot fibers may have on their use as transmission medium, and during attenuation testing.

The key issues related to fibers used in fire resistant cables are:

- high levels of thermal radiation in multimode fibers, up to $-36 \mathrm{dBm}$ from a $33 \mathrm{~m}$ long fiber at $1000^{\circ} \mathrm{C}$,

- fast deterioration of the fiber, occurring after $1-2 \mathrm{~h}$ at $1000^{\circ} \mathrm{C}$,

- sudden fiber failures above $900^{\circ} \mathrm{C}$.

\subsection{Plans Concerning Further Work}

The nature of defects responsible for optical and mechanical deterioration of fibers at high temperatures deserves further research that will focus on explaining rapid fiber failures that occurred in our experiments. Cracks initiate a fiber break even with moderate cable bends (see Fig. 4). The cable will fail faster during the fire test and will be given a lower certification rating.

In the future, we plan to test fibers in a typical loose tube, as well as fibers encased in a hermetic metallic tube to prevent ingress of air and simulate real conditions in a cable subjected to fire. A detailed inspection of rapidly damaged samples will be performed as well to explain the failure mechanism and to determine whether it may affect a fiber in a cable.

After documenting, in this paper, the effects of high temperatures on fused silica fibers, we plan to perform a separate study focusing on means capable of remedying this type of interference. Proper selection of wavelength and the photodetector, together with optional use of an optical bandpass filter, may eliminate the problem during transmissions. For attenuation measurements of fibers during fire tests, a cyclic procedure of automatic background calibration and compensation was found to be effective; filtering offers the extra improvement needed. A switch of the wavelength at which attenuation changes of OM1-OM5 multimode fibers are measured from $1300 \mathrm{~nm}$ (stipulated in most standards) to $850 \mathrm{~nm}$ is strongly recommended in order to reflect all current applications.

\section{Conclusions}

The experiments performed on standard telecom fibers confirmed that:

- fused silica fibers heated to temperatures typical of fires $\left(800-1000^{\circ} \mathrm{C}\right)$ may emit thermal radiation that is strong enough to disrupt attenuation measurements and data transmission;

- intensity of this radiation depends on the diameter of the fiber core and $\mathrm{OH}$ content, being the strongest in multimode fibers and negligible in $\mathrm{OH}$-free ("low water peak") single mode fibers; 
- radiation originating from $\mathrm{OH}-$ contaminated fibers is concentrated in $\mathrm{OH}$ absorption bands, mostly $1383 / 1393 / 1407 \mathrm{~nm}$, and can be blocked by bandpass filters;

- prolonged heating of pristine fibers to $800-1000^{\circ} \mathrm{C}$ results in a gradual escape of water, in a decrease of the fiber's thermal emission (beneficial), in the creation of defects causing light scattering, in coupling of thermal radiation from hot surroundings into the fiber and in its mechanical deterioration by cracking (harmful);

- the change of fiber attenuation resulting from heating alone is below $0.1 \mathrm{~dB} / \mathrm{m}$;

- several fiber samples failed rapidly when heated above $900^{\circ} \mathrm{C}$, losing their optical continuity, probably due to surface contamination.

\section{References}

[1] D. Homa, G. Pickrell, and A. Wang, "Investigation of high temperature silica based fiber optic materials", DOE Award No. DEFE0027891, Virginia Polytechnic Institute \& State University, 2018 [Online]. Available: https://www.osti.gov/servlets/purl/1489125

[2] A. Honda, K. Toh, S. Nagata, B. Tsuchiya, and T. Shikama, "Effect of temperature and irradiation on fused silica optical fiber for temperature measurement", J. of Nuclear Materials, vol. 367, pp. 1117-1121, 2007 (DOI: 10.1016/j.jnucmat.2007.03.193).

[3] Standard EN-IEC 60793-1-40, "Optical fibres - Part 1-40: Attenuation measurement methods" [Online]. Available: https://standards.iteh.ai/catalog/standards/clc/ a4ce5f5b-006b-4ad2-a1c1-9dddbb796f22/en-iec-60793-1-40-2019

[4] Standard EN 60793-1-46, "Optical fibres - Part 1-46: Measurement methods and test procedures - Monitoring of changes in optical transmittance" [Online]. Available: https://standards.iteh.ai/catalog/ standards/clc/dd4c92a8-dba8-498c-84a4-412ff1cc3d9a/ en-60793-1-46-2002

[5] Standard IEC TR 62222, "Fire performance of communication cables installed in buildings" [Online]. Available: https://standards.iteh.ai/catalog/standards/iec/ 53462b01-8540-4799-8986-57812f68c23f/iec-tr-62222-2012

[6] Standard EN 60332-1-2, "Tests on electric and optical fibre cables under fire conditions - Part 1-2: Test for vertical flame propagation for a single insulated wire or cable - Procedure for $1 \mathrm{~kW}$ pre-mixed flame" [Online]. Available: http://bityl.pl//nGQV

[7] Standard IEC 60332-3-10, "Tests on electric and optical fibre cables under fire conditions - Part 3-10: Test for vertical flame spread of vertically-mounted bunched wires or cables - Apparatus" [Online]. Available: https://standards.iteh.ai/catalog/standards/clc/ 6e572ecb-4b4c-4f6a-8478-27c773b76c8f/en-iec-60332-3-10-2018

[8] Standard IEC 60332-3-24, "Tests on electric and optical fibre cables under fire conditions - Part 3-24: Test for vertical flame spread of vertically-mounted bunched wires or cables - Category C" [Online]. Available: https://standards.iteh.ai/catalog/standards/clc/ Ofa90869-905f-46a2-9f58-40c8ea2647c4/en-iec-60332-3-24-2018

[9] Standard IEC 60332-3-25, "Tests on electric and optical fibre cables under fire conditions - Part 3-25: Test for vertical flame spread of vertically-mounted bunched wires or cables - Category D" [Online]. Available: https://standards.iteh.ai/catalog/standards/clc/ ffcbafe8-6378-4298-868f-6267e848e20c/en-iec-60332-3-25-2018

[10] Standard EN 50399, "Common test methods for cables under fire conditions. Heat release and smoke production measurement on cables during flame spread test. Test apparatus, procedures, results" [Online]. Available: https://standards.iteh.ai/catalog/standards/ clc/aec73708-d180-4cf3-b532-fb0850ed0705/pren-50399
[11] Standard IEC 61034-1, "Measurement of smoke density of cables burning under defined conditions - Part 1: Test apparatus" [Online]. Available: https://global.ihs.com/doc_detail.cfm?document_ name $=$ IEC \%2061034\%2D1\&item_s_key $=00134074$

[12] Standard IEC 61034-2, "Measurement of smoke density of cables burning under defined conditions - Part 2: Test procedure and requirements" [Online]. Available: https://standards.iteh.ai/catalog/ standards/clc/e39b159f-d63f-40a4-835b-df2ec023a31a/ en-61034-2-2005-a2-2020

[13] Standard IEC 60754-1, "Test on gases evolved during combustion of materials from cables - Part 1: Determination of the halogen acid gas content" [Online]. Available: https://standards.iteh.ai/catalog/ standards/clc/fe208672-6841-4787-be72-f420fa4a3b5a/ en-60754-1-2014

[14] Standard IEC 60754-2, "Test on gases evolved during combustion of materials from cables - Part 2: Determination of acidity (by $\mathrm{pH}$ measurement) and conductivity" [Online]. Available:

https://standards.iteh.ai/catalog/standards/clc/6f7e97c5-a648480f-838a-c0be9ab5fa8e/en-60754-2-2014-a1-2020

[15] Standard IEC 60754-3, "Test on gases evolved during combustion of materials from cables - Part 3: Measurement of low level of halogen content by ion chromatography" [Online]. Available: https://standards.iteh.ai/catalog/standards/iec/ 2bf8bd77-cea9-44a5-8079-7ccbe4f35f8b/iec-60754-3-2018

[16] Standard IEC 60331-1, "Tests for electric cables under fire conditions - Circuit integrity - Part 1: Test method for fire with shock at a temperature of at least $830^{\circ} \mathrm{C}$ for cables of rated voltage up to and including $0,6 / 1,0 \mathrm{kV}$ and with an overall diameter exceeding $20 \mathrm{~mm}$ " [Online]. Available: https://standards.iteh.ai/catalog/standards/ iec/ffa2c2dd-6239-4799-b3a4-1da3312d4c40/iec-60331-1-2018

[17] Standard IEC 60331-2, "Tests for electric cables under fire conditions - Circuit integrity - Part 2: Test method for fire with shock at a temperature of at least $830^{\circ} \mathrm{C}$ for cables of rated voltage up to and including $0,6 / 1,0 \mathrm{kV}$ and with an overall diameter not exceeding $20 \mathrm{~mm}$ " [Online]. Available: https://standards.iteh.ai/catalog/standards/ iec/2740c2d9-7e8d-43ba-aac0-ef2ffe17fd2c/iec-60331-2-2018

[18] Standard IEC 60331-3, "Tests for electric cables under fire conditions - Circuit integrity - Part 3: Test method for fire with shock at a temperature of at least $830^{\circ} \mathrm{C}$ for cables of rated voltage up to and including $0,6 / 1,0 \mathrm{kV}$ tested in a metal enclosure" [Online]. Available: https://standards.iteh.ai/catalog/standards/iec/ f76a006a-8ae7-4588-adb1-ebd9c419744a/iec-60331-3-2018

[19] Standard EN 50200, "Method of test for resistance to fire of unprotected small cables for use in emergency circuits" [Online]. Available: https://standards.iteh.ai/catalog/standards/clc/ 873a9c45-a35b-4ec0-b0d3-ab1fcc792af4/en-50200-2015

[20] Standard EN 50575, "Power, control and communication cables. Cables for general applications in construction works subject to reaction to fire requirements" [Online]. Available: https://standards.iteh.ai/ catalog/standards/clc/b8675c9d-b3b4-4a46-ae9e-7207aca441cb/ en-50575-2014

[21] Standard DIN 4102-12, "Fire behaviour of building materials and elements - Part 12: Fire resistance of electric cable systems required to maintain circuit integrity - Requirements and testing" [Online]. Available: https://standards.globalspec.com/std/365477/din-4102-12

[22] Standard EN 50582, "Procedure to assess the circuit integrity of optical fibres in a cable under resistance to fire testing" [Online]. Available: https://standards.iteh.ai/catalog/standards/clc/ 7403ddfd-5ea6-4eb0-83bd-feb5fff0e3f2/en-50582-2016

[23] Arpita Mitra, Inna Kouzmina, and Maritza Lopez, "Thermal stability of the CPC fiber coating system", Corning White Paper, vol. 4250, 2010 [Online]. Available: https://www.corning.com/ microsites/coc/oem/documents/specialty-fiber/WP4250-ThermalStability-of-the-CPC-Fiber-Coating-System.pdf

[24] A. A. Stolov, D. A. Simoff, and J. Li, "Thermal stability of specialty optical fibers", J. Lightwave Technology, vol. 26, no. 20, pp. 34433451, 2008 (DOI: 10.1109/JLT.2008.925698).

[25] "Reliability test report for SR15-9/125-ACL (SM Fiber with high temperature resistant acrylate coating)", Fujikura, 2013 [Online]. Available: http://www.fujikura.co.jp/eng/products/optical/ appliedoptics/02/__icsFiles/afieldfile/2013/02/04/td4013.pdf 
[26] Specification KA2001R1, "Technoflame FOC-2-SLT-HFFR E30/ PH120 4x50/125 OM2 fibre optic safety cables", Technokabel S.A., 2020.

[27] FiberTek, "Armoured(SWA) fire resistant LSZH loose tube fiber optic cable - IEC 60331 FTSF-FLTFMAPSZ(FR): Steel CSM, mica wrapped jelly filled tube, aluminium moisture barrier, PE inner sheath, steel wire armoured, LSZH outer sheath", Rev0.0 (Mar17 C-IN1703111), 2017 [Online]. Available:

https://www.vectorinfotech.com/FileStore/Full/ _Product92560_FTSF-FLTFMAPSZ(FR)_Rev0.0(Mar17).pdf

[28] Standard IEC 60793-2-10:2019: Optical fibres - Part 2-10: Product specifications - Sectional specification for category A1 multimode fibres [Online]. Available: https://standards.iteh.ai/catalog/standards/ iec/b85d8886-7454-46ed-b3e5-a2cc5ef12952/iec-60793-2-10-2019

[29] Recommendation ITU-T G.652, "Characteristics of a single-mode optical fibre and cable", 2016 [Online]. Available: https://www.itu.int/rec/dologin_pub.asp?lang=e\&id=T-REC-G.652201611-I!!PDF-E\&type=items

[30] Recommendation ITU-T G.657, "Characteristics of a bending-loss insensitive single-mode optical fibre and cable", 2016 [Online]. Available: https://www.itu.int/rec/dologin_pub.asp?lang=e\&id=TREC-G.657-201611-I!!PDF-E\&type=items

[31] Standard EN-IEC 60793-2-50, "Optical fibres - Part 2-50: Product specifications - Sectional specification for class B single-mode fibres" [Online]. Available: https://standards.iteh.ai/catalog/standards/ clc/7ddb02c1-80c1-440c-a200-c95c0ca056fd/ en-iec-60793-2-50-2019

[32] Standard ISO/IEC 11801, "Information technology - Generic cabling for customer premises", 2017 [Online]. Available: https://www.iso.org/standard/66182.html

[33] Standard ISO 834-1:1999, "Fire-resistance tests - Elements of building construction - Part 1: General requirements" [Online]. Available: https://www.iso.org/standard/2576.html

[34] OFS Fitel, "AllWave optical Fiber - Zero Water Peak: The industry's first zero water peak single-mode fiber for reliable full-spectrum performance", 2017 [Online]. Available: https://www.ofsoptics.com/ wp-content/uploads/AllWave-117-web-7.pdf

[35] OFS Fitel, "AllWave FLEX+ Fiber - Zero Water Peak: Optimized bend performance and reliable low loss transmission for in-building, central office and cabinet applications", 2016 [Online]. Available: https://fiber-optic-catalog.ofsoptics.com/documents/pdf/ AllWave-FLEX-PLUS-144-web.pdf

[36] M. Pellow-Jarman and M. Hetem, "Comparison of the thermal degradation products of poly(butylene terephthalate) and flame retardant poly(butylene terephthalate) formulations using a pyrolysis FTIR cell”, Polymer Degradation and Stability, vol. 47, no. 3, pp. 413-421, 1995 (DOI: 10.1016/0141-3910(95)00006-2).

[37] P. K. Johnston, E. Doyle, and R. A. Orzel, "Acrylics thermal decomposition products and toxicity", $J$. of the American College of Toxicology, vol. 7, no. 2, pp. 139-200 1988 (DOI: $10.3109 / 10915818809014519)$.

[38] A. H. Rose and T. J. Bruno, "The observation of $\mathrm{OH}$ in annealed optical fiber", J. Non-Cryst. Solids, vol. 231, no. 3, pp. 280-285, 1998 (DOI: 10.1016/S0022-3093(98)00676-0).

[39] A. H. Rose, "Devitrification in Annealed Optical Fiber", J. of Lightwave Technol., vol. 15 , no. 5, pp. 808-814, 1997 (DOI: 10.1109/50.580819).

[40] T. Shikama, K. Toh, S. Nagata, B. Tsuchiya, and Y. Ohno, "Temperature measurement by thermal luminescence of partially replaced core optical fiber", J. of Nuclear Materials vol. 386-388, pp. 1023-1026, 2009 (DOI: 10.1016/j.jnucmat.2008.12.204)

[41] OFS Fitel, " $50 \mu \mathrm{m}$ graded-index OM2 - bend-insensitive multimode optical fiber", 2018 [Online]. Available: https://fiber-optic-catalog.ofsoptics.com/documents/pdf/ Graded-Index-50-Fibre-Data-Sheet.pdf

[42] Fujikura, "Fujikura FutureGuide-MM50 Multi Mode Fiber (ITUT G.651): Multi mode fiber with $50 \mu \mathrm{m}$ of core diameter (ITUT G.651) short-reach optical transmission for LAN in offices and premises", 2020 [Online]. Available: https://www.fujikura.co.jp/ products/optical/opticalfibers/01/2044175_11306.html
[43] O. Humbach, H. Fabian, U. Grzesik, U. Haken, and W. Heitmann, "Analysis of $\mathrm{OH}$ absorption bands in synthetic silica", J. of NonCrystalline Solids, vol. 203, pp. 19-26, 1996 (DOI: 10.1016/0022-3093(96)00329-8).

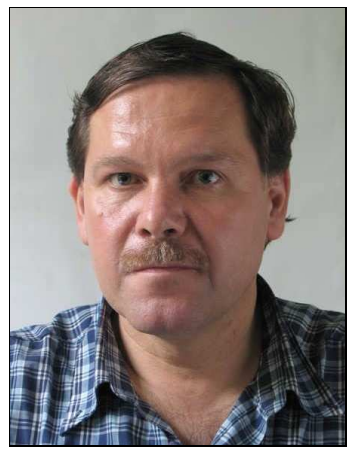

Krzysztof Borzycki received his M.Sc. in Electrical Engineering from Warsaw University of Technology, Warsaw, Poland in 1982, and Ph.D. degree in Communications Engineering from the National Institute of Telecommunications (NIT), Warsaw, Poland in 2006. He has been NIT since 1982, except for the time spent on developing DWDM solutions at the Ericsson AB R\&D Center in Stockholm, Sweden, in 2001-2002. $\mathrm{He}$ is currently an Assistant Professor at the NIT Central Chamber for Telecommunication Metrology. His areas of interest include fiber access networks (FTTx), testing and standardization of fiber cables and passive components, monitoring of fiber and copper cable networks, security of optical networks and effects of high temperatures in fused silica fibers. He also works as an instructor and lecturer specializing in fiber optics, fiber testing and splicing. Dr. Borzycki has participated in multiple European research programs, including COST-270, COST-299, COST TD1001 and NEMO, and is a member of Cables and Fiber Optics Work Groups of the Polish National Standardization Committee (PKN).

(i) https://orcid.org/0000-0001-6066-6590

E-mail: k.borzycki@il-pib.pl

National Institute of Telecommunications

Szachowa 1

04-894 Warsaw, Poland

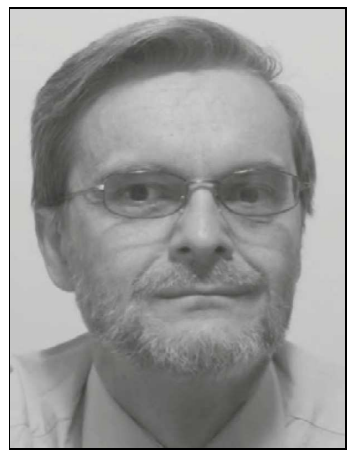

Marek Jaworski received his Ph.D. degree from the National Institute of Telecommunications (NIT), Warsaw, Poland, in 2001. He is currently an Assistant Professor at the NIT Central Chamber for Telecommunication Metrology. He has been with NIT since 1982, working on modeling and design of optical fiber transmission systems, measurement methods, and test equipment for optical networks. His current research interests include numerical simulations of telecommunication systems, advanced modulation formats, and nonlinear photonics.

(iD) https://orcid.org/0000-0002-6742-4874

E-mail: m.jaworski@il-pib.pl

National Institute of Telecommunications

Szachowa 1

04-894 Warsaw, Poland 


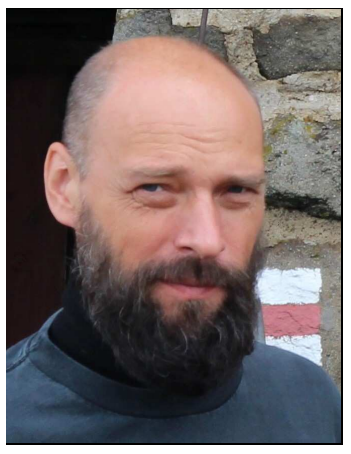

Tomasz Kossek received his M.Sc. in Optoelectronics and a $\mathrm{Ph} . \mathrm{D}$. degree from Warsaw University of Technology, Warsaw, Poland, in 1996 and 2002, respectively. $\mathrm{He}$ is currently an Assistant Professor at the National Institute of Telecommunications Poland, Warsaw. His current research interests include optoelectronic measurements and their calibration, laser physics, and optical communication.

(D) https://orcid.org/0000-0001-6670-2871

E-mail: t.kossek@il-pib.pl

National Institute of Telecommunications

Szachowa 1

04-894 Warsaw, Poland 